Resources for the 21st Century: Summary and Conclusions of the International Centennial Symposium of the U.S. Geological Survey

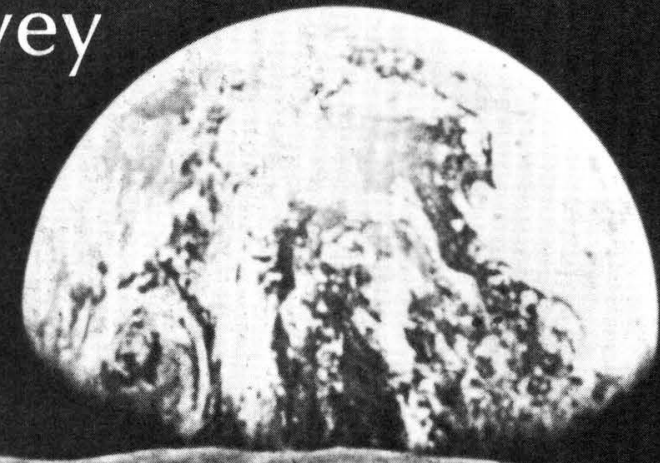

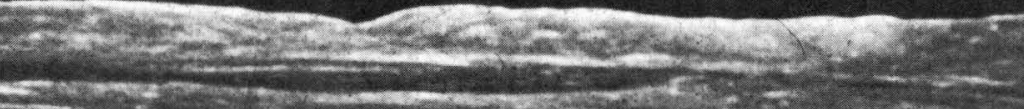

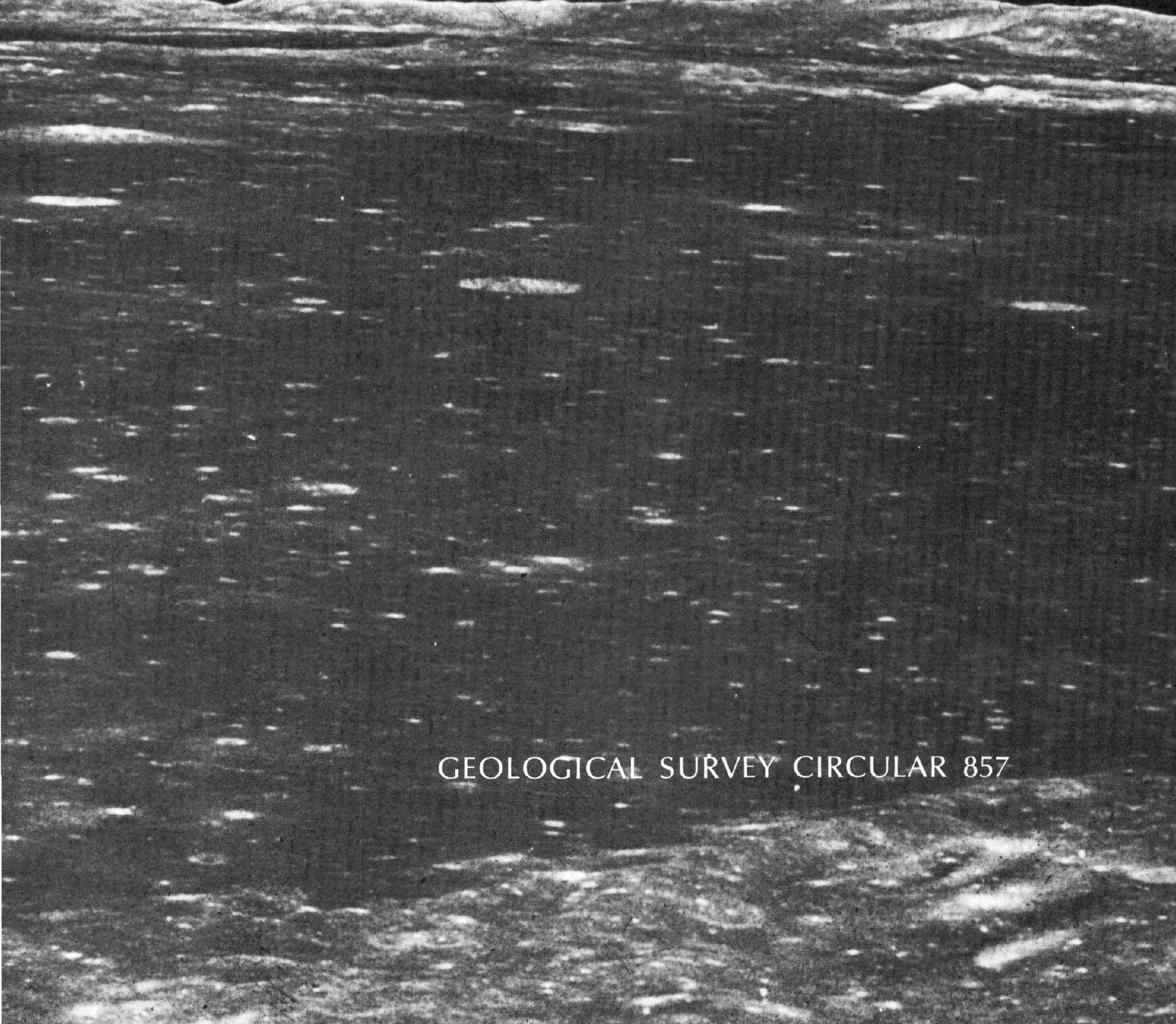



Resources for the 21st Century:

Summary and Conclusions of the

International Centennial Symposium of the U.S. Geological Survey

By Frank C. Whitmore, Jr.

$\begin{array}{llll}\text { GEOLOGICAL SURVEY CIRCULAR } 857 & \text { CR }\end{array}$ 
United States Department of the Interior JAMES G. WATT, Secretary

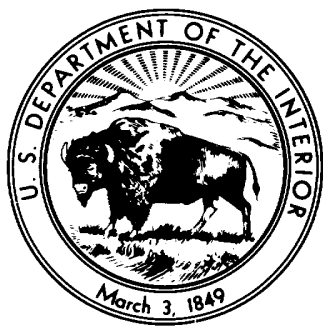

Geological Survey

Dallas L. Peck, Director

Library of Congress catalog-card No. 81-600163

Free on application to Branch of Distribution. U.S. Geological Survey 604 South Pickett Street, Alexandria, Virginia 22304 


\section{CONTENTS}

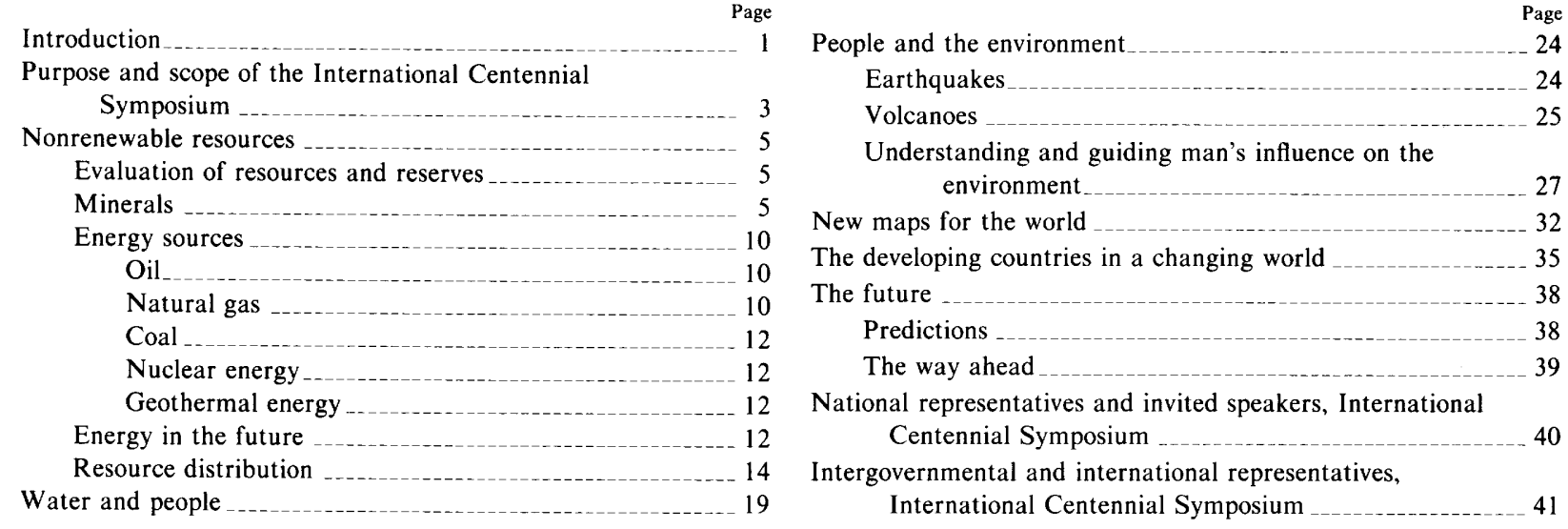





\title{
Resources for the 21st Century: Summary and Conclusions of the International Centennial Symposium of the U.S. Geological Survey
}

\author{
By Frank C. Whitmore, Jr.
}

\section{INTRODUCTION}

In 1879 , the U.S. Geological Survey was established by the Congress for the purpose of mapping our geologically unknown West so that its resources and its environment could be known and used well. The United States was a developing nation whose leaders, both political and scientific, foresaw the need for accurate, documented knowledge of agricultural land and mineral resources as well as of the topography of country that had to be traversed by road and rail. We are proud of the foresight of our predecessors, for they were interested not only in developing the land wisely but also in providing an understanding of the environment that would enable people to live in harmony with their surroundings. In the arid West a century ago, the U.S. Geological Survey laid the ground work for understanding what would now be called a fragile environment. The questions asked then were direct and pragmatic. How much land would it take to support a family? What climatic fluctuations could be anticipated? What water resources were available in a land of marginal rainfall? What minerals might be commercially developed?

But it is to the credit of our founders that the exploration that they set in motion was not devoted exclusively to immediate problems. The search for valuable minerals was, of course, a matter of prime interest, but the focus of the early studies was upon thorough interpretation of the geology of the region - a basic approach that was to prove fruitful through the years.

The first leaders of the U.S. Geological Survey inherited a tradition of government scientific exploration that embraced all natural science, in foreign lands as well as in the territory of the United States. The first such American enterprise, the Wilkes Expedition of 1838 to 1842 , exemplified this ideal in its collection of scientific data and specimens from many different places. But the goal of the new U.S. Geological Survey in 1879 was limited to exploration of the western territories of the United States. This limitation is understandable, for the West, despite previous exploration, was still poorly known, and pressure for settlement and development was great. It must have seemed at that time that the resources of the United States were infinite - that there were more than enough for all. But it was the beginning of a century that was to see a revolution in human life, both population and the use of natural resources growing at rates that dwarfed anything in the previous history of the world. And so, at the end of the U.S. Geological Survey's first century, we find ourselves in a different world - on a small planet whose growing demand for resources and increasing environmental problems must be the concern of all. The nations of the world are interdependent; no longer can any nation be self-sufficient or isolated.

In recent years, this interdependence has been exemplified by the U.S. Geological Survey in its development of cooperative relationships with scientists and scientific groups in other countries on a governmentto-government basis. In fact, we now have working agreements with more than 100 countries. Therefore, in celebrating our Centennial with the firm purpose of looking at the future, we invited our colleagues from 


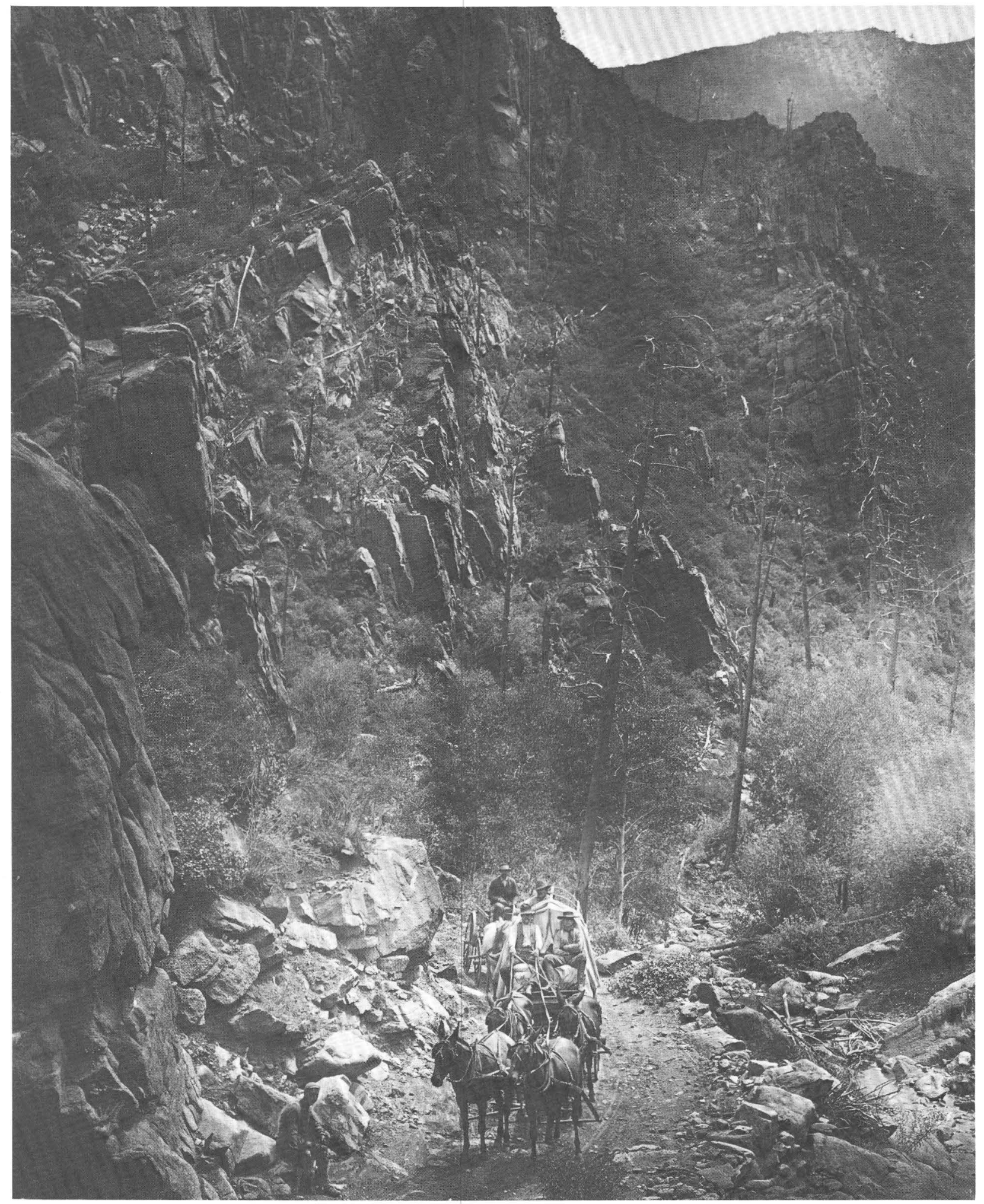

U.S. Geological Survey party en route from Garden Park to Cripple Creek, Colo., in 1894. U.S. Geological Survey photograph by Whitman Cross. 
other countries to join us in examining the challenges that face us all as we approach the 21 st century.

All told, 468 participants from 41 countries and 13 international organizations attended the International Centennial Symposium, held at the National Center in Reston, Virginia, from October 14 to 19,1979 . They represented more than 3,000 million people living on 96 million square kilometers of the Earth's surface on 6 continents. We are grateful to our friends for joining us, for their presence was evidence of strong international interest in solving mutual problems; their contribution of ideas is a material step toward achieving such solutions. We thank the participants for contributing papers to this symposium, and we are especially pleased that the meeting stimulated enthusiastic, informal discussion before, during, and long after the formal sessions.

During the week of the International Centennial Symposium, an impressive community of thought gradually emerged as earth scientists and government planners expressed substantial concerns for the future of natural resources in the world community. The widely diverse backgrounds of the participants make that sense of common cause a vital one. It is the purpose of this publication to summarize the major ideas and conclusions that resulted from the October 1979 meeting.

The Proceedings of the Symposium (Professional Paper 1193) will present, in detail, the data on which usable projections into the resources future must be based. By offering here a distillate of the thoughts expressed, I have treated these data as the collective product of the deliberations of this distinguished group. Instead of summarizing the remarks of each contributor, I have presented a synthesis of concurring and differing opinions expressed in the course of the week's discussions. No direct quotations are given, although some statements are paraphrased. As General Chairman of the Symposium, my aim is to highlight what seem to be the general conclusions suggested by the presentations and discussions, to which all those present contributed.

I am grateful to Philip W. Guild, Charles D. Masters, Vincent E. McKelvey, Donald R. Nichols, and Morris M. Thompson for thoughtful review of the manuscript and to Mary Ellen Williams for help in its preparation.

\section{PURPOSE AND SCOPE OF THE INTERNATIONAL CENTENNIAL SYMPOSIUM}

The Centennial of the U.S. Geological Survey comes at a critical juncture in our history. Our socioeconomic affairs, our political interactions, and our encounters with physical phenomena are shared as never before. World population has grown from 2,500 million in 1950 to 4,200 million today, an increase of 70 percent. Material demands in the same period have grown even faster. World trade has increased by 570 percent; world energy use has increased more than fivefold on a tonnage basis; the value of manufactures, mostly of mineral origin, has increased 10 times. In the 30 years after the end of World War II, man consumed more minerals than he had in all previous history. This escalation emphasizes the need for painstaking analysis of present trends in order to understand and attempt to solve the problems of the future.

No man is an island, nor, in the sense of isolation from the rest of the world, is any country. The energy crisis of recent years has brought this fact home to us brutally, but energy is only one of the resource problems that we must face. In mineral resources as well, diverse natural occurrences may develop the same kind of world problems that energy has already demonstrated, but the potential complications are much greater because of the number of commodities involved.

The role of each nation as producer and consumer differs from that of every other nation, and, in this regard, the contrast between developed and developing countries is great. This symposium was, therefore, organized so that countries at widely varying levels of development could describe their resource problems and the approaches that they are taking to solve them.

As will be seen, these problems are by no means all scientific; economic nationalism, internal political priorities, and financing - both internal and externalwere discussed and received much attention.

For the purposes of this Symposium, "resources" were broadly defined to include not only minerals, energy, land, and water but also the quality of our total environment as it is influenced by natural hazards, such as earthquakes and volcanoes, and by man himself.

Besides these resources, implicit in every consideration was the most important resource of all-people. Geologists and other scientists, engineers of all kinds, economists, government officials, financiers and businessmen, technicians, agriculturists, and the labor force at large will, as they do now, play a notable part in the discovery, development, distribution, and use of 


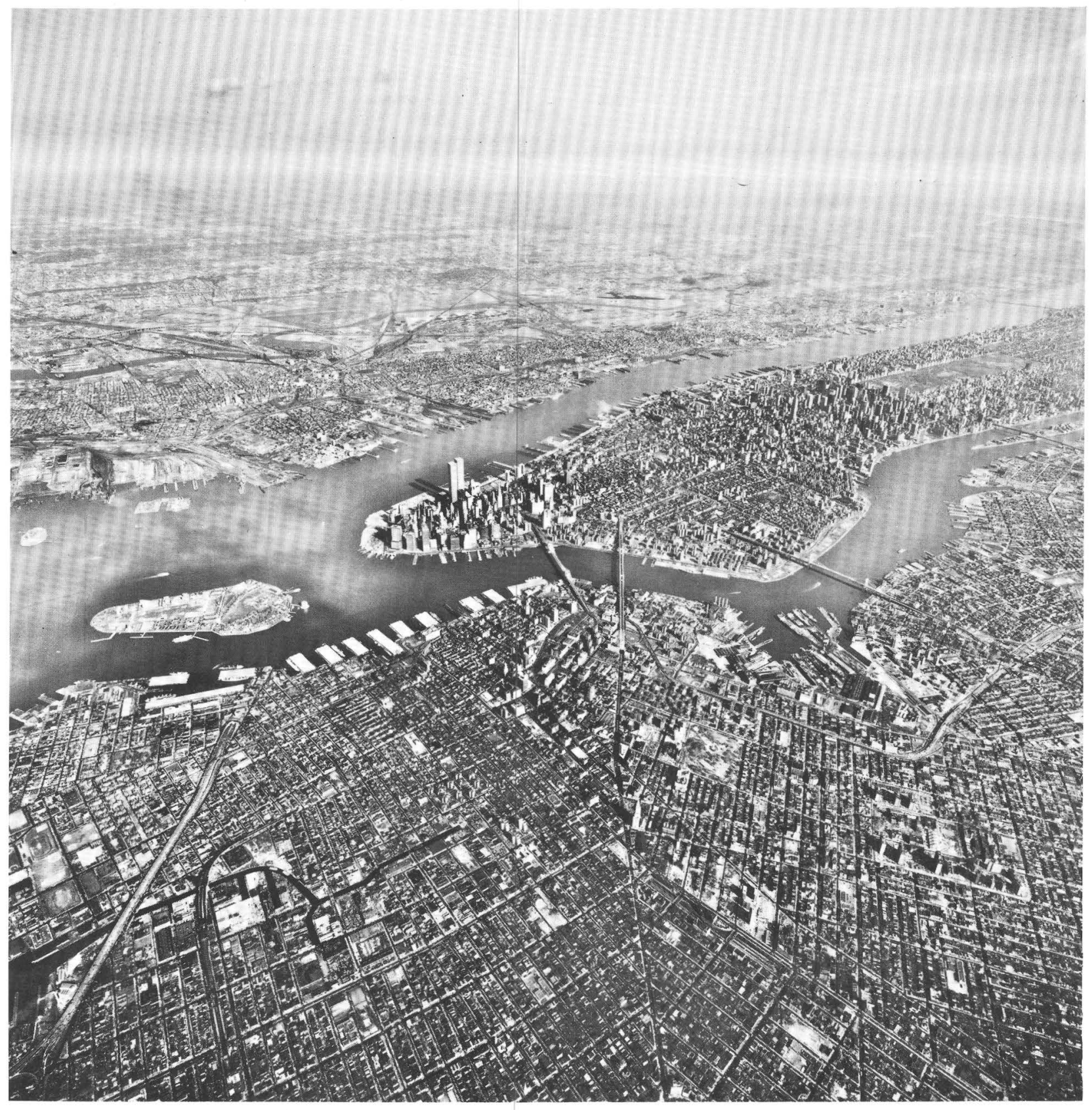

Part of New York City (population 7,071,030). 
all resources; the timely supply of such personnel and their most effective use must be assured.

In planning the Symposium, we realized that knowledge of resources is of no use unless it is correctly recorded and published-made public for the public. For this reason, technological advances in surveying, mapping, cartography, and printing of geologic maps were included among the important subjects of discussion.

\section{NONRENEWABLE RESOURCES}

\section{Evaluation of resources and reserves}

Planning for the future requires knowledge of the nature, amount, and distribution of nonrenewable resources-known mineral deposits, whether they are economically recoverable or not, and unknown deposits whose existence is only supposed. National and international mineral and energy policy is only as good as the data on which it is based, and past experience has shown that estimates of resources, even when they are prepared by qualified experts, can vary widely. Estimates of reserves - that is, identified deposits economically minable now - are based on geologic mapping and subsurface exploration, but, to estimate potential resources, one must extrapolate from known occurrences to inferred bodies of minerals that can be neither seen nor measured now. This process is further complicated by economic aspects; what can be mined economically now, and what might be minable in the future? Three major factors bear upon this question. First, improving technology can increase reserves without making new discoveries. Second, changes in price-cost ratios can redefine reserves in terms of what can be profitably exploited. Third, discovery of new, economically workable deposits may increase the reserve figure, or the new deposits may replace previously worked bodies and leave the reserve estimate unchanged.

In the past, estimating resources has been difficult; in the future, it will be more so. Known higher grade and large deposits are being exhausted. In spite of rising costs, it is becoming necessary to utilize lower grade deposits or those situated in remote or difficult environments that in the past have not been feasible to work. Such remote areas are so poorly known that, without much field study, future estimates of resources and reserves would probably be less accurate than present estimates. Overcoming this difficulty will require evaluation of the mineral resources of such large, difficult areas as the Amazon Basin, where work is already underway by the Brazilian Government. Much effort of this type will need to be expended in the developing countries and will require financial and (or) technical support beyond the ability of these countries to supply. International agencies and programs such as the International Geologic Correlation Program can be instrumental in improving the basic data on which our resource estimates must rest.

Beyond the physical assessment of resources and their accessibility lie the political factors that affect their availability. It has already been demonstrated that limiting production or export as a national policy can create shortages of either worldwide or local nature, even when physical evaluation has shown that adequate reserves exist. It is likely that political and economic factors will become increasingly significant in the future.

In planning for the 21 st century, human resources as well as mineral resources must be considered. In the developed countries, the supply of technical personnel has kept pace with demand. In some developing countries, however, a major effort must be made in the next two decades to overcome this lack of manpower and to persuade those who are trained to remain in their home countries.

Another aspect of human resources is the size of the labor force. In some developing countries, or at least in parts of them, labor-intensive methods of mining and mineral processing may be preferable to mechanical methods, especially in the exploitation of small mineral deposits. Thus, another factor is added to overall resource evaluation.

\section{Minerals}

Although there is little prospect of serious mineral shortages in this century from a global point of view, such a prospect does exist on an individual-country basis, especially if we consider advanced industrialized but resource-poor societies such as Japan, western Europe, and even the United States and perhaps the Soviet Union. In these countries, effective depletion of a number of traditional domestic mineral resources has already occurred.

A shift away from mineral self-sufficiency is inevitable also in developing countries. Korea is an example. After being a mineral exporter in the 1950's, Korea changed over to intensive industrialization and high economic growth in the 1960's. Consequently, there was a dramatic shift in a few years from export of iron to import and from self-reliance in copper to import. The country is still self-reliant for lead, but the gap between supply and demand is narrowing. Concurrent 


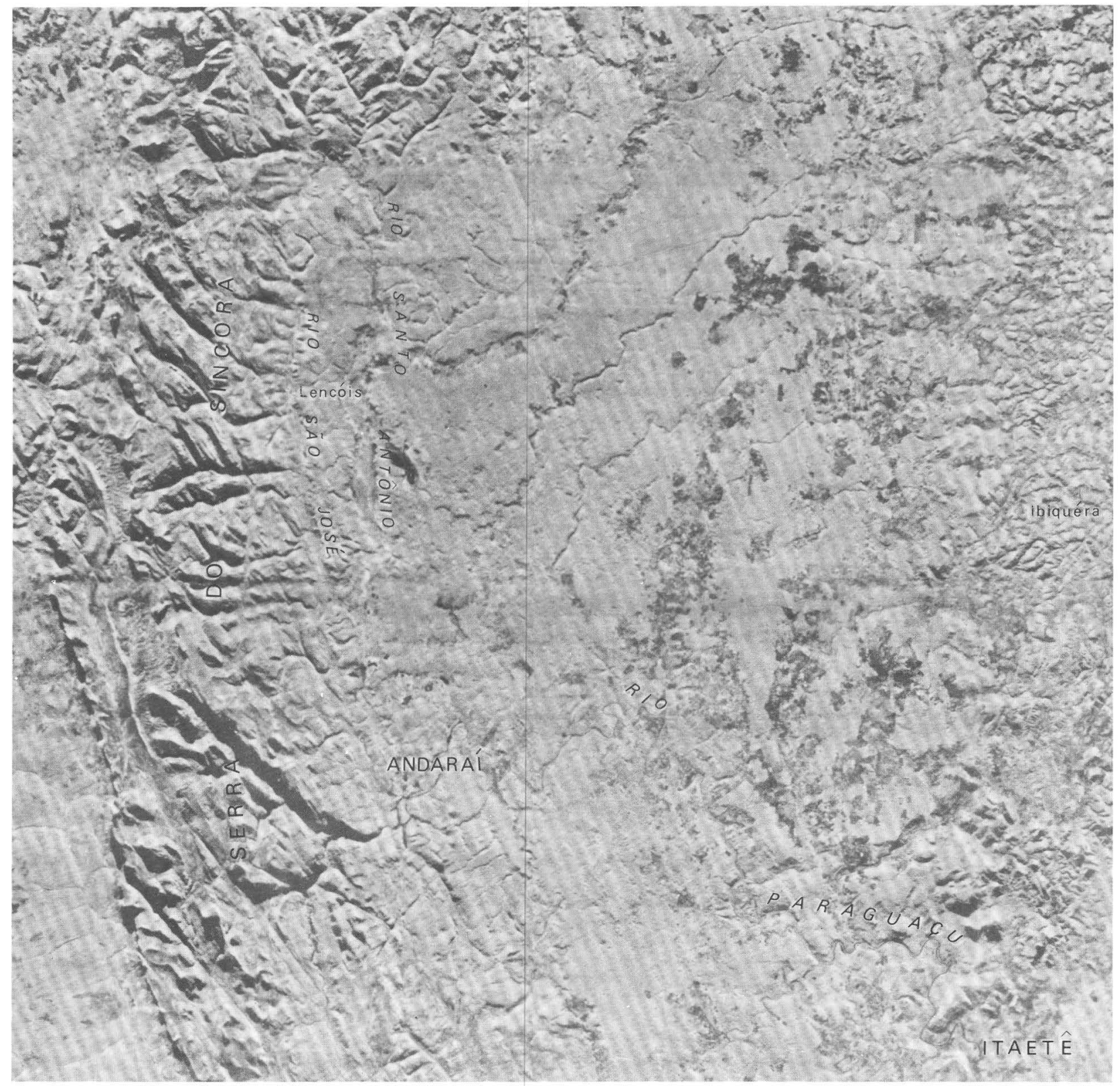

Detail of an experimental RADAM map (here reproduced in black and white) printed during Projeto RADAMBRASIL. Planimetric features are surprinted in red, black, and blue line color on the original lithographic monotone base map. The airborne side-looking radar images were computer enhanced by U.S. Geological Survey staff, who also gave cartographic and special technical training to the Federal and commercial mapmakers who have developed the screenless process for regular use in Brazil. 


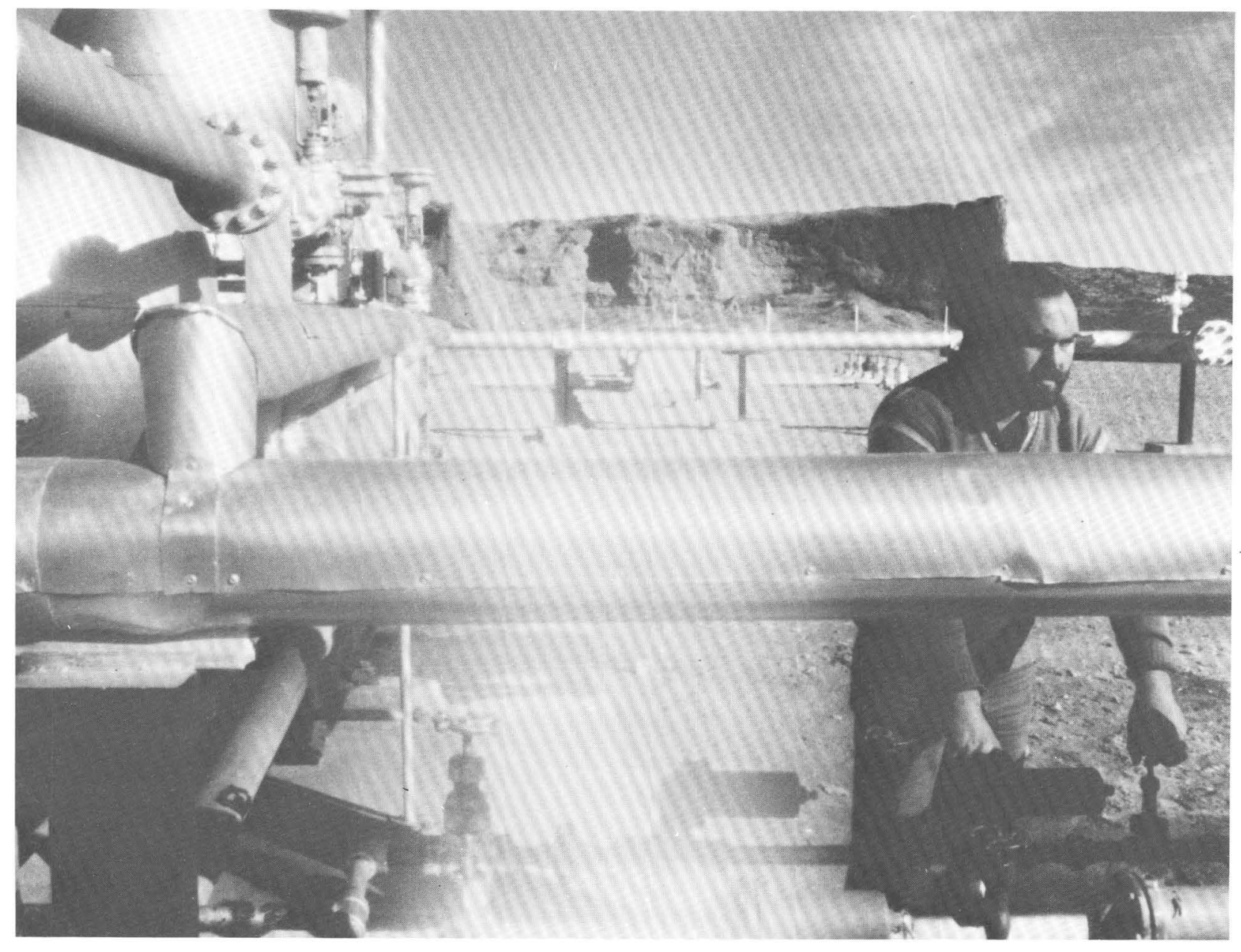

"Argentina is a model for developing countries in respect to the function it can perform in the harnessing of energy" (D. A. Brunella). Workman in the Loma la Lata oilfield.

with industrial development, reliance on imported energy has risen sharply, from 9.4 percent in 1962 to 51.2 percent in 1971 and 66.8 percent in 1978. Petroleum accounted for 61.2 percent of Korea's 1978 imports.

Another expectable concomitant of Korean industrialization has been a change from labor-intensive to resource-consuming heavy industry. Unless significant progress is made in locating large concealed mineral deposits, Korea will remain an importer for some of its most critical needs.

Discovery of concealed mineral deposits is, in fact, a major world hope for the future. On the basis of estimated crustal abundance, characteristics of known outcropping deposits, and metallogenic studies of favorable geologic terrain, there is reason to suggest that undiscovered minable deposits remain to be found and that further exploration is worthwhile.

In South America, for example, the geologic setting of the countries of the Andean Cordillera (Chile, Peru,
Bolivia, Ecuador, Colombia, and the western part of Argentina) almost surely will support increases in the production of both metallic and nonmetallic minerals as soon as more intensive and extensive exploration is advanced or concluded. In Mexico, an estimated 1.5 million square kilometers requires exploration at a semidetailed level; at least half of this area needs detailed geological and geophysical exploration.

The eastern and southeastern parts of Venezuela, the northern and northwestern parts of Brazil, and Surinam, which lie on the Amazon and Orinoco cratons, have enormous potential for additional mineral discovery. Eastern Paraguay also has good mineral potential. These areas, mainly overlying a Precambrian shield, offer a challenge in contrast to that offered by the Cordillera and Mexico, areas in which we are mostly concerned with deeper deposits perhaps as deep as 1,000 m. Vast areas of Precambrian shield, on the other hand, are covered by tropical rain 


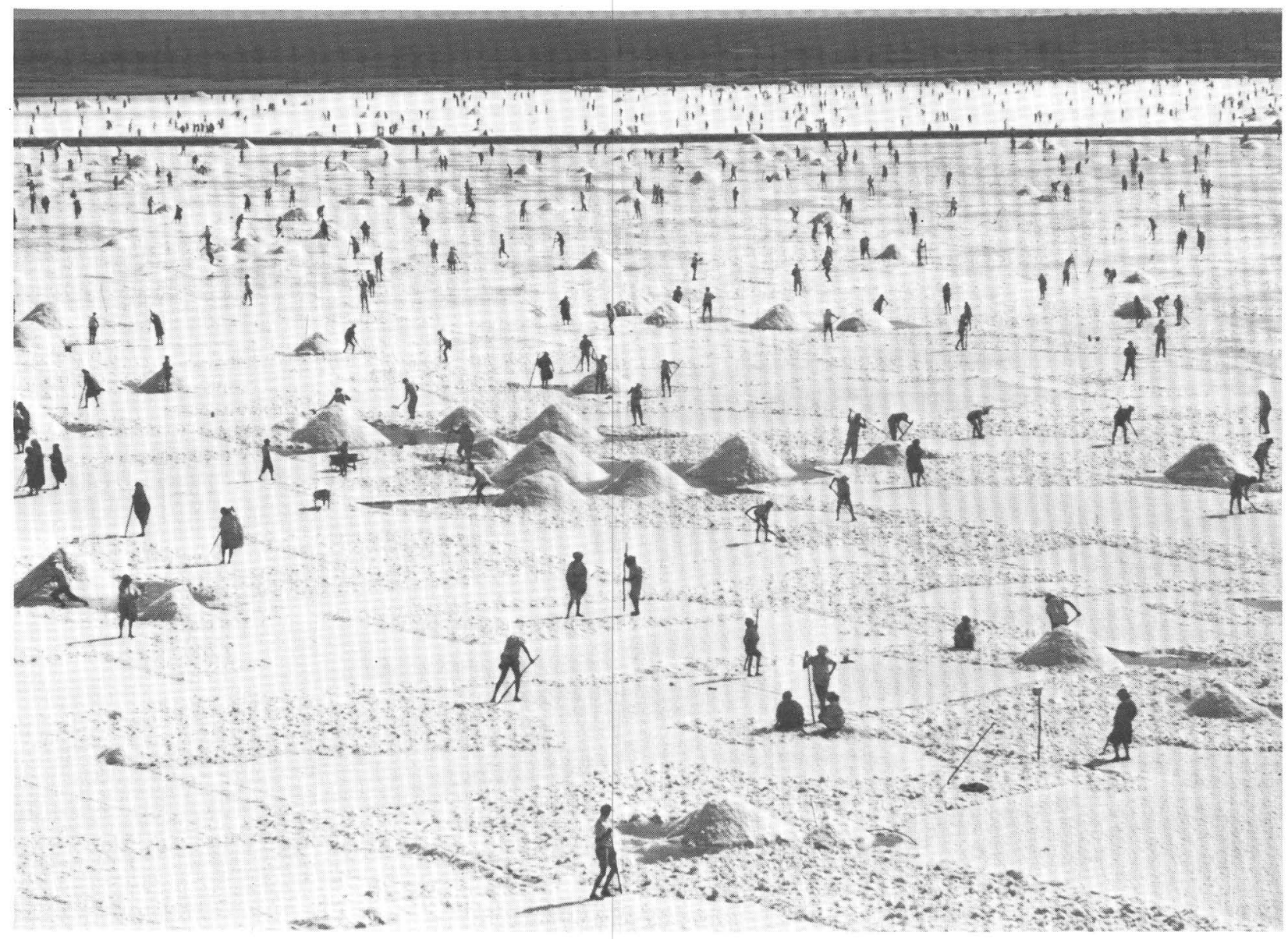

Guajiro Indians harvesting sun-dried salt at Manaure, Colombia, the last unmechanized flats of the national salt industry. Photograph by Loren McIntyre, copyright by National Geographic Society.

forest, and so even near-surface deposits must be explored for by novel techniques. Precambrian shields, both within and outside the tropics, now contribute much of our nickel, iron, uranium, platinum, gold, and manganese and substantial quantities of many other metals. We can conclude that unexplored tropical rain-forest areas have similar mineral potential. The Brazilian exploration program in the Amazon area has demonstrated the special techniques necessary for mineral exploration in tropical jungles. Evaluation by side-looking airborne radar is followed up by ground examination of selected areas that are reached by helicopter. Logistical problems and the lack of outcrops owing to vegetation cover and deep weathering render such work slow and costly. In Arctic areas also, the environment poses difficulties of the same magnitude. Besides these spectacular and difficult regions, many more accessible areas, especially ones with complex geologic structure, remain to be geologically mapped at a scale large enough to allow determination of their mineral potential.

The pressure for additional mineral supplies will lead inevitably to exploration for deep mineral deposits - perhaps as deep as 1,000 m or more. Such exploration will require improved technology and methodology.

Future exploration, in summary, must encompass (1) unexplored surface areas susceptible to investigation by conventional means; (2) areas of hidden nearsurface deposits where special techniques are required; and (3) deep deposits. A great deal of this exploration will be done in developing countries, but much exploration, especially for hidden or deep deposits, remains to be done in developed countries. An added factor, already evident, is the necessity of exploiting both small and low-grade deposits. For such exploitation, we are faced with increased costs per unit produced. On the one hand, large, low-grade deposits inevitably 


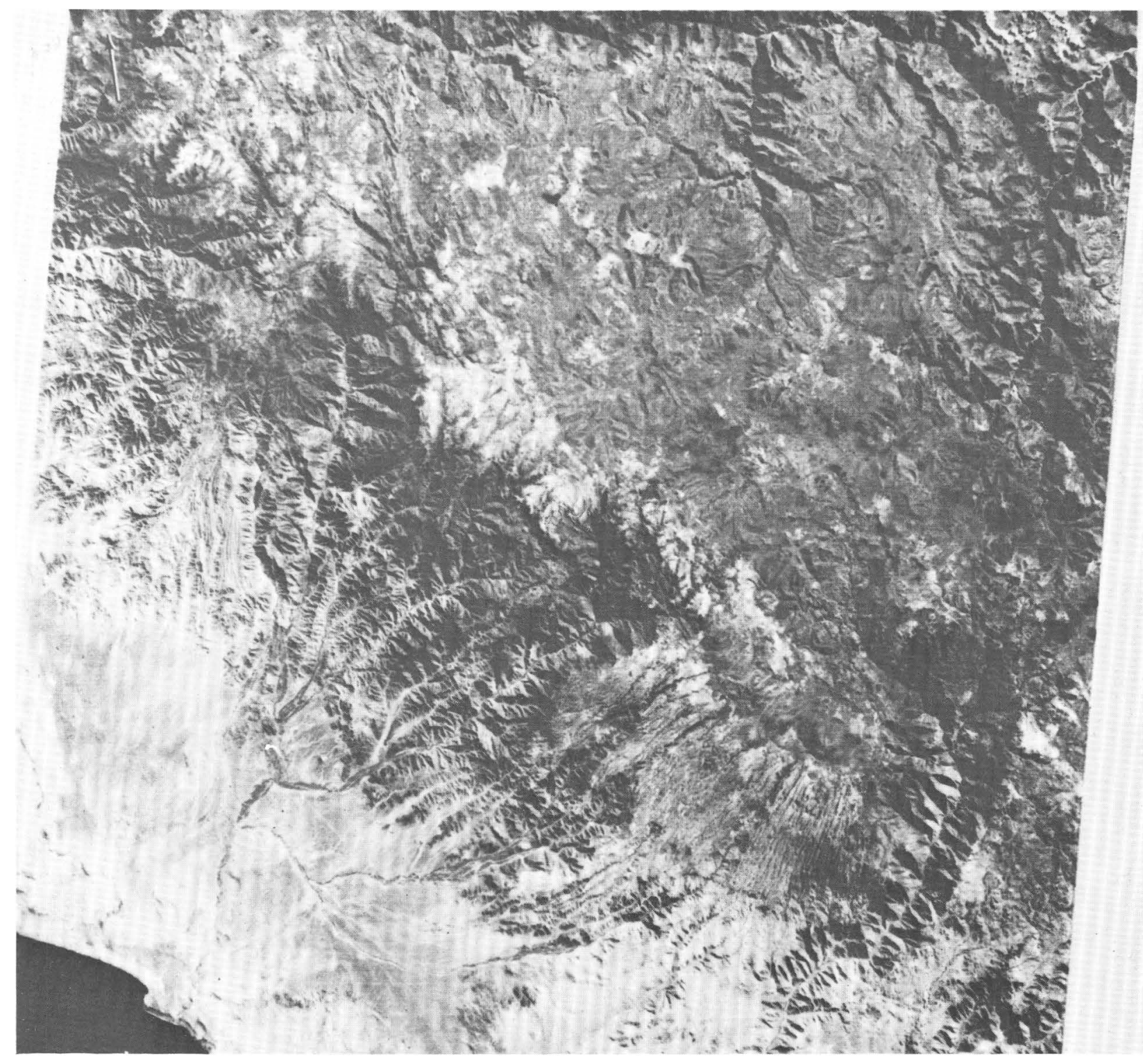

Peruvian Andes (upper right) and coastal plain (lower left) $320 \mathrm{~km}$ southeast of Lima. National Aeronautics and Space Administration Landsat image 1645-14255, April 29, 1974, reproduced in black and white. 


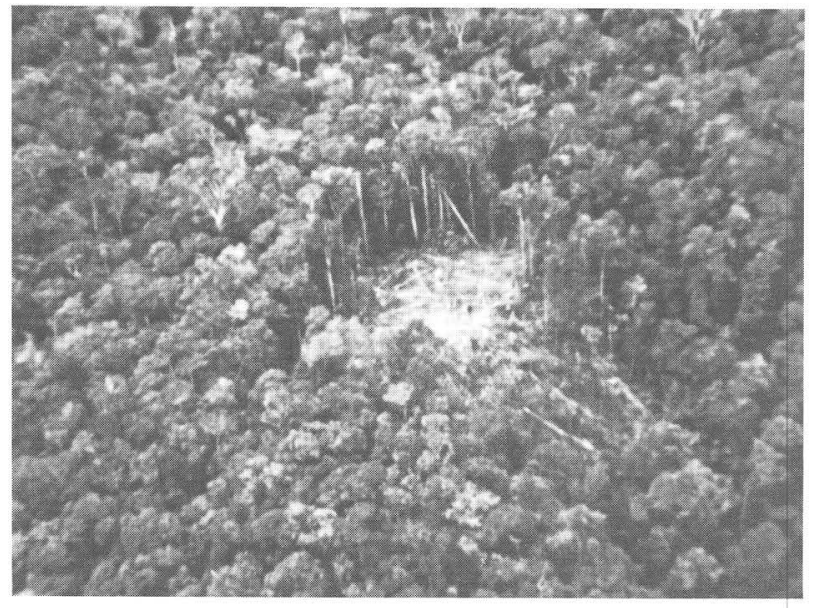

Amazon jungle clearing opened to allow technicians to make field observations in inaccessible regions. Photograph by Otto Bittencourt.

require energy-intensive, highly mechanized exploitation. Small deposits, on the other hand, may be worked most efficiently in a labor-intensive way, a method that may best suit countries with large populations and relatively low levels of technology.

\section{Energy sources}

The revolution in petroleum supply that has taken place in the past decade greatly alters our perspective in trying to predict energy needs and resources for the 21 st century. In terms of cost, energy will be a far more significant factor in future planning than it has been in the past. Experience with petroleum also teaches us that availability and price of energy sources are not simple matters of supply and demand; political considerations can be at least as strong as economic ones.

Under the pressure generated by restricted supply and rising prices, new patterns of energy use will develop. It is probable that the pattern of supply and pricing, often dictated by political considerations, will be seen in world trading in minerals as well as in fuels.

Oil. At present, oil is the dominant world energy resource, but its importance, although great, is transitory. Total petroleum discoveries to 1980 are about $140 \times 10^{9} \mathrm{t} ; 60 \times 10^{9} \mathrm{t}$ has been produced, and $80 \times 10^{9} \mathrm{t}$ remains as proved reserves. The importance of oil in the world economy stemmed from its ease of utilization and from exceptionally low production costs resulting from equally exceptional geological and political conditions. These conditions no longer obtain, but it is inevitable that, even under the less advantageous terms, the world must continue for some time to be heavily dependent upon oil. Because of the difficulties and the time needed to shift to other, more diversified energy sources, it is of the utmost importance to assess how long the oil era can or will last.

If future needs are to be estimated, some assumptions must be made: What will the world population be? What will the per capita use of energy be? What will the energy be used for? One estimate presented at the Symposium uses the following assumptions: (1) World population stabilized at less than 12 billion people, possibly between 7 and 9 billion; (2) energy needs also stabilized or increasing very slowly; and (3) liquid fuels reserved for transportation, petrochemicals, and development of less developed countries. On this basis, world oil use would need to be at least 3 to 5 billion tons per year, much less than present consumption. According to some studies, conventional oil would be available in quantities sufficient to meet a demand for 5 billion tons per year until the year 2010; the supply would drop to 3 billion tons per year by the year 2030 . However, the effect of rising prices upon the profitability of "difficult" oil (for example, Venezuelan heavy oil) and upon production from small fields may increase available supplies.

Since the 1973-1974 crisis, the United States and Canada have dramatically increased their search for oil and gas; search has also been intensified by the United Kingdom, Norway, and Mexico. In the opinion of some Symposium participants, conventional oil exploration, spurred by the incentive of rising prices, can maintain supplies long enough for us to make the shift to unconventional sources of oil, provided that the United States synfuel program and the Canadian tar sands program pave the way and also that world consumption and (or) production of oil increases much more slowly than previous forecasts have indicated. Such a shift can, in turn, allow time for broadening our energy-mineral base.

Another more optimistic opinion holds that a large percentage of the world's giant petroleum fields have not yet been found. If further exploration shows this assumption to be true, more time will, of course, be available for making the transition to other sources of energy.

Natural gas. Large-scale use of natural gas began much later than that of oil and is still restricted to fewer countries, but the regional distribution of natural gas is wider than that of oil. One estimate of total recoverable natural gas resources is about 227 trillion cubic meters, including 64 trillion cubic meters as reserves and 162 trillion cubic meters as undiscovered resources. The 1978 net world production of about 1.435 trillion cubic meters gives a static lifetime of 


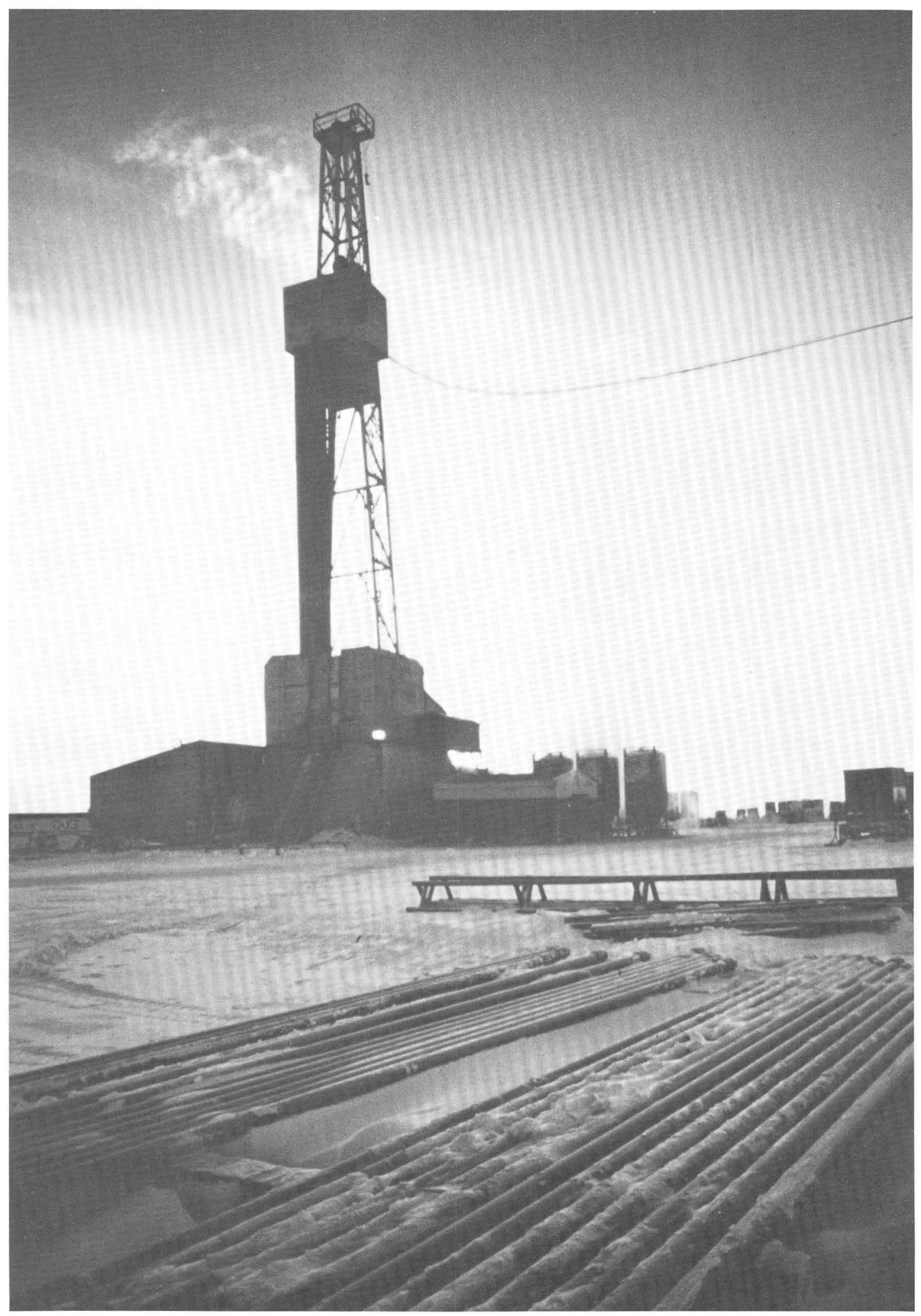

Oil rig at Prudhoe Bay on the North Slope of Alaska. Photograph courtesy of Conoco, Inc. 


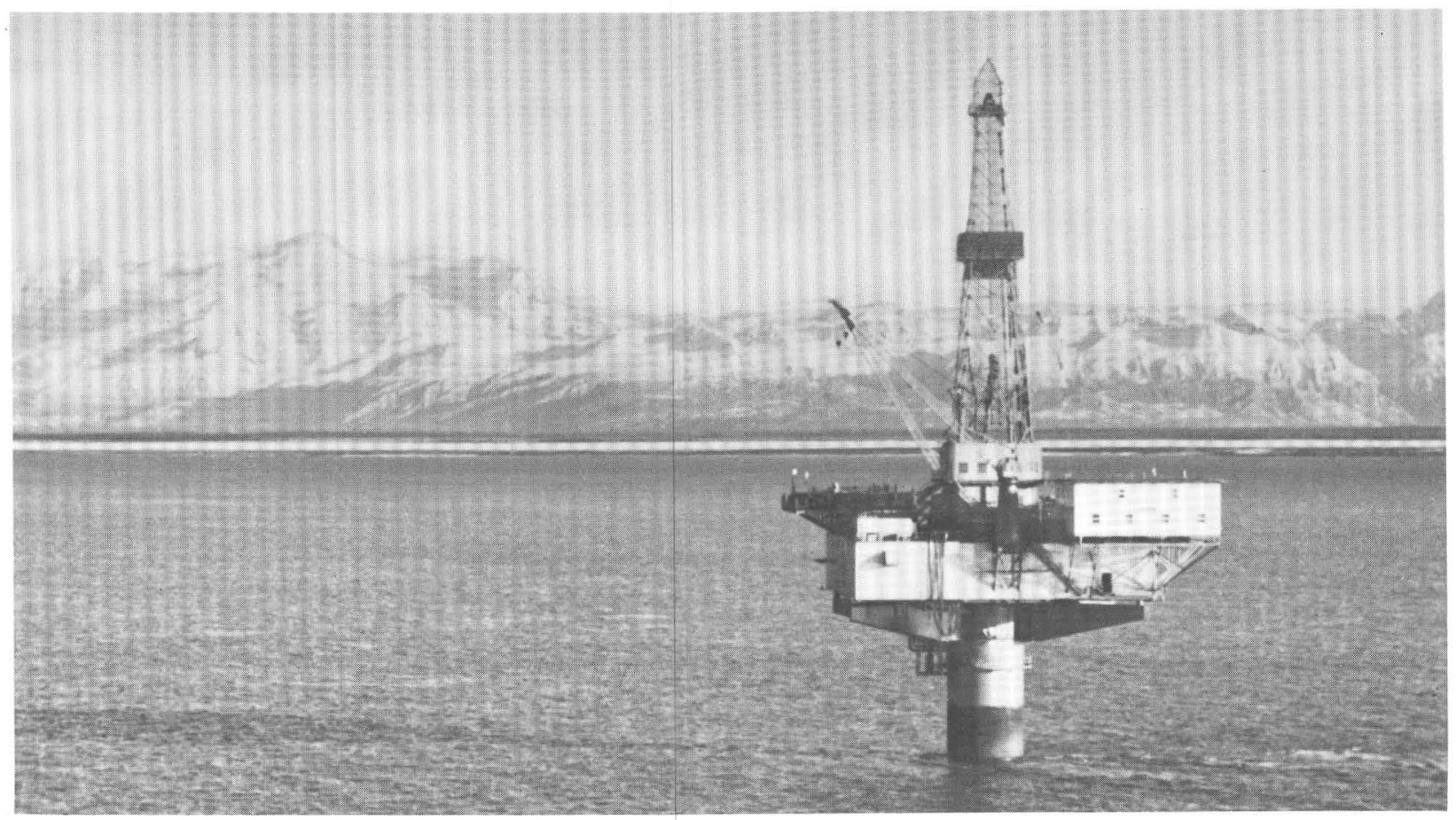

Trading Bay monopod platform on site in Cook Inlet, Alaska. Photograph courtesy of Marathon Oil Company.

about 50 years for the reserves and about 160 years for the total recoverable resources. Static lifetime, of course, is not a very reliable indicator of the real life of gas or other mineral resources; increased rates of consumption (the rule of the past) may reduce the life of presently prospective resources, and technologic advance that brings within economic reach presently unusable sources (also the rule of the past) may extend the life of natural gas resources.

Coal. With resources of 10,000 billion $\left(10^{12}\right)$ tons and reserves of 636 billion tons, coal seems the most promising energy resource for the 21 st century. In 1977, world coal production was 2,988 million tons. Over the last 10 years, the average annual increase in coal production has been 1.2 percent. At this rate of increase, present production could continue for 100 to 130 years. Coal technology, such as gasification and liquefaction, will assume increasing importance.

Nuclear energy. The total cumulative world demand for uranium to the middle of the 21 st century may be as much as 20 million tons. If so, 17 or 18 million tons beyond presently known resources would be required. It was argued at the Symposium that this picture is not as grim as it looks; the demand for uranium is still relatively new in comparison with that for many other minerals, and, therefore, major areas remain to be explored.

About 85 percent of the world's reasonably assured and estimated additional resources of uranium are in
Australia, Canada, France and French-controlled areas, South Africa, and the United States. Thus, as petroleum becomes less important, the energy political situation could be very different in the 21 st century.

Geothermal energy. Investment in geothermal energy is small. At present, its use is limited to volcanic or tectonically active zones where hot water or steam occurs naturally. A process now being developed may increase the use of this type of energy; hot dry rock technology involves pumping water into fracture zones in rocks whose temperatures are greater than $150^{\circ} \mathrm{C}$. Although it is unlikely to be a major world energy source, the unexploited potential of geothermal energy may prove to be important on a local or even on a regional basis.

\section{Energy in the future}

It was generally agreed that price is one of the most crucial factors in determining what energy sources are sought, produced, and used. In the field of petroleum, high prices can be both a deterrent to use and an incentive to exploration. India, for instance, cannot afford to pay high prices for oil and therefore will accelerate exploration. The same is true of Egypt, which is already producing oil. Economic balance must be weighed against energy balance in determining the feasibility of producing energy from unconventional 


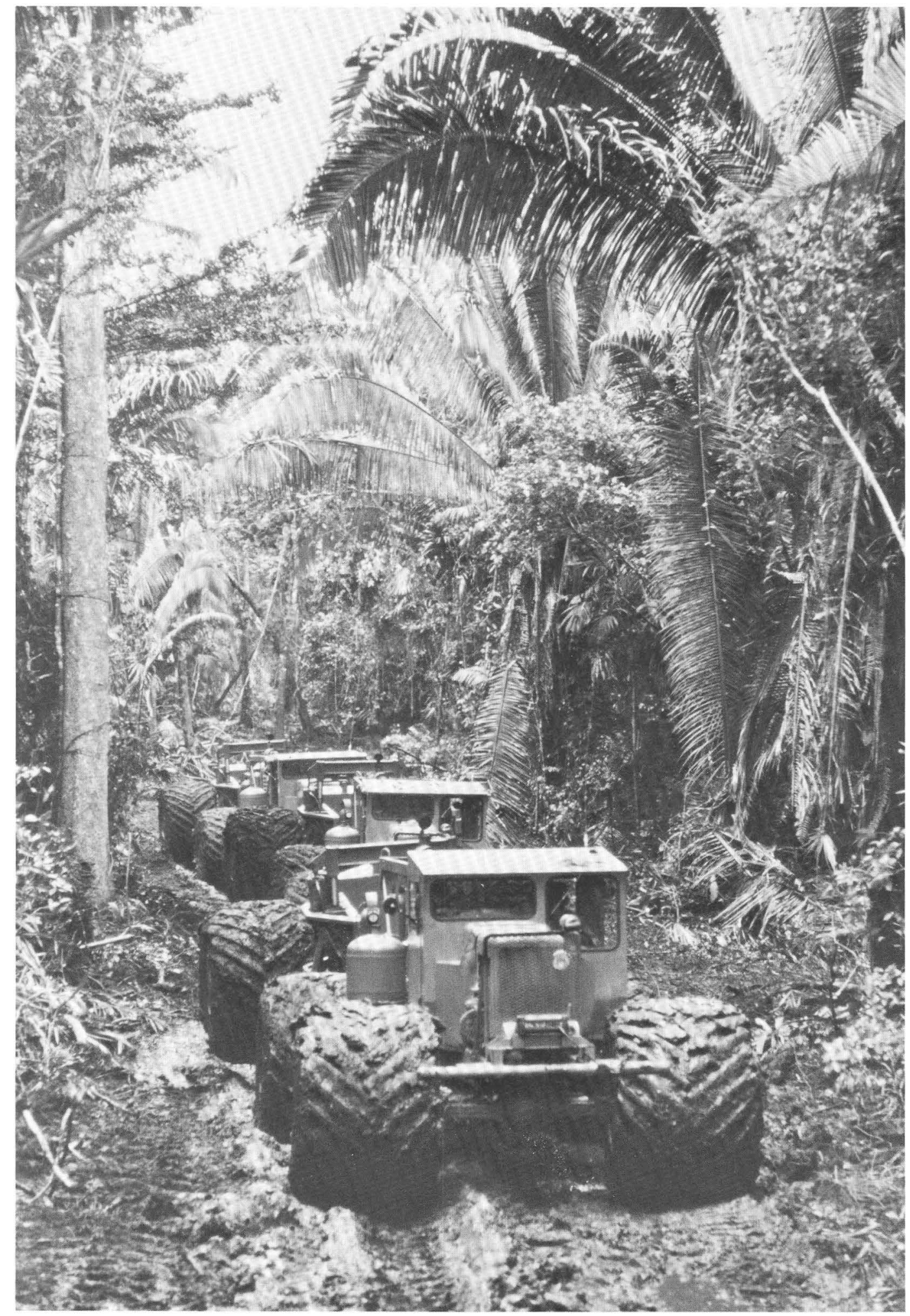

Vehicles carrying vibrators engaged in seismic subsurface survey in Belize, Honduras. Photograph by Michael E. Long, copyright by National Geographic Society. 


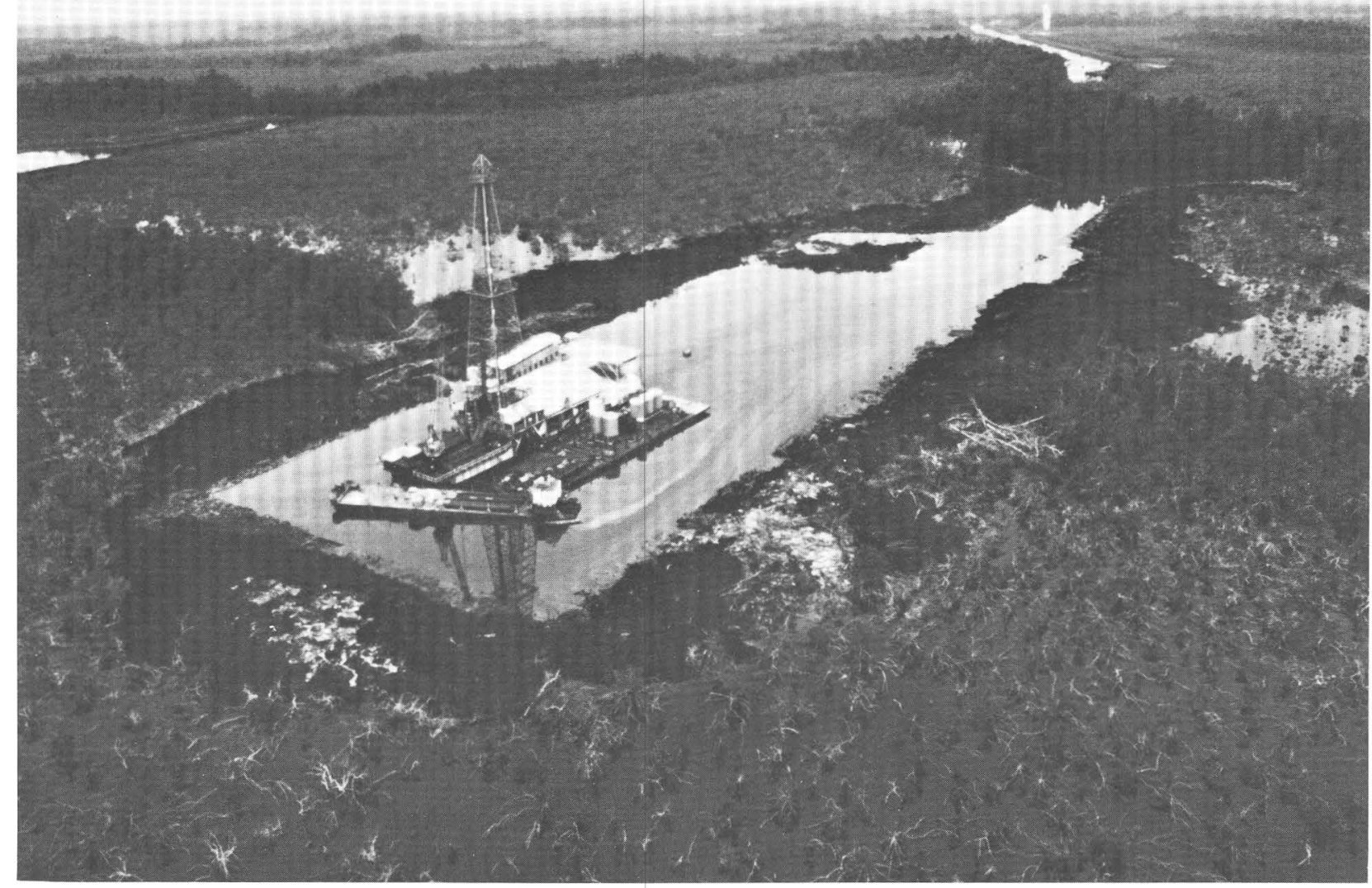

Drill rig in the Niger delta. Photograph by Bruno Barbey, copyright by National Geographic Society.

sources. For example, in calculating the feasibility of producing oil that requires more extensive refining, the added energy cost of production is likely to be decisive.

\section{Resource distribution}

A lesson learned from the oil crisis and readily extrapolated to other mineral commodities is that mineral resources are unevenly distributed. In the past, in peacetime, such inequalities have been ironed out by the play of the international marketplace. It is now becoming apparent that the national policies of producing countries can cause local mineral shortages. The problem thus becomes political rather than economic or scientific. The major mineral prospects for the future are most probably located in undeveloped parts of the world, and such areas are increasingly less open to exploitation by outsiders. We are at present in a transi- tional period with regard to development of mineral deposits in hitherto unworked areas. Developing nations regard their mineral resources as a national heritage to be managed for their own good; the resultant policies, however, may lead to hesitancy on the part of potential foreign investors. As awareness of world mineral interdependence increases and as the influence of international organizations, including groups of countries united by common economic problems, grows, many of these problems may be resolved.

The rapid economic growth of many Third World nations is already leading to the discovery and development of previously unexploited mineral areas. Since detailed exploration of remote and difficult areas is in its early stages, it is probable that the distribution pattern of known world mineral resources will change in the coming decades, perhaps with a significant effect on world economics. 


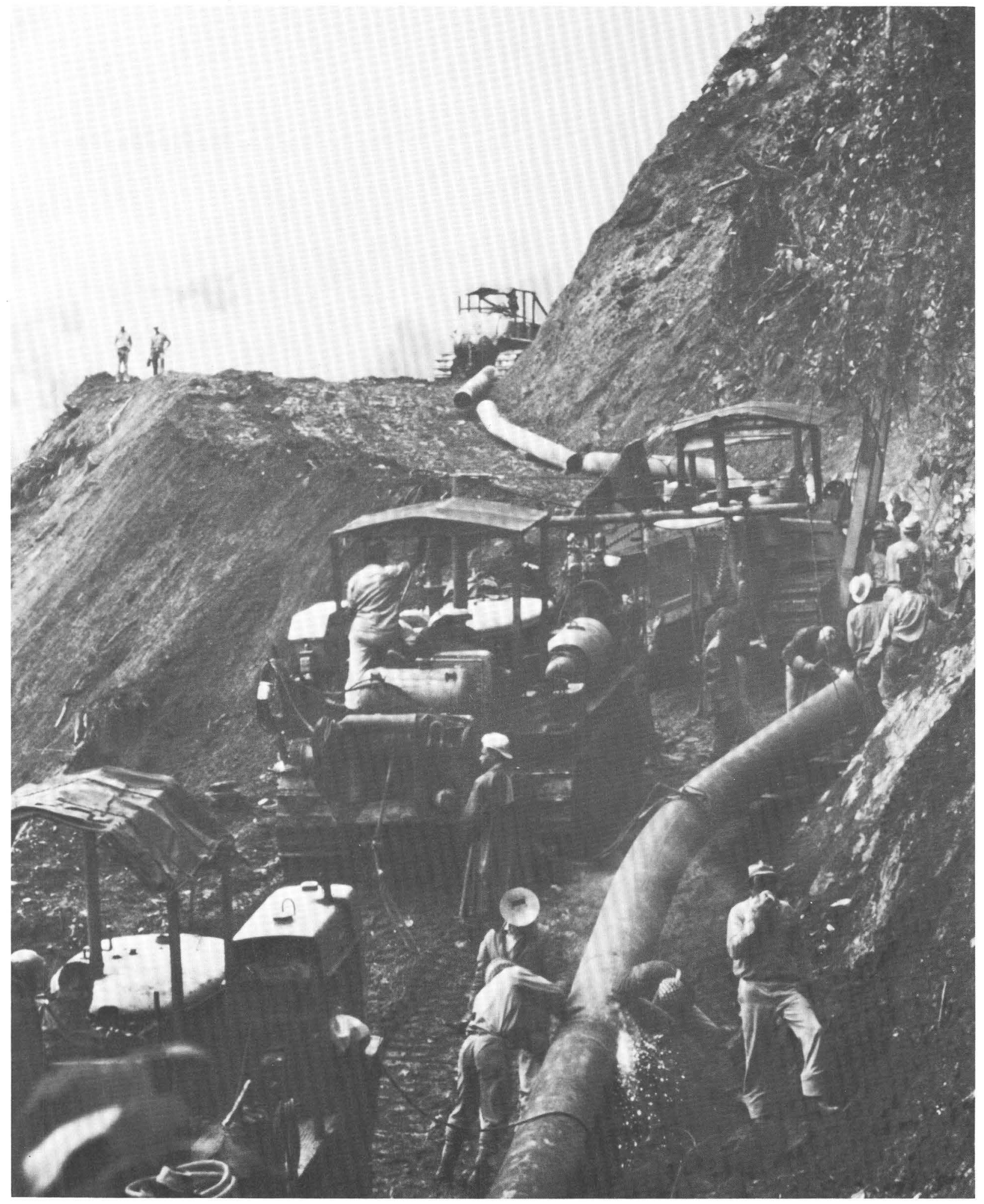

Laying an oil pipeline in Colombia. Photograph by Loren McIntyre, copyright by National Geographic Society. 


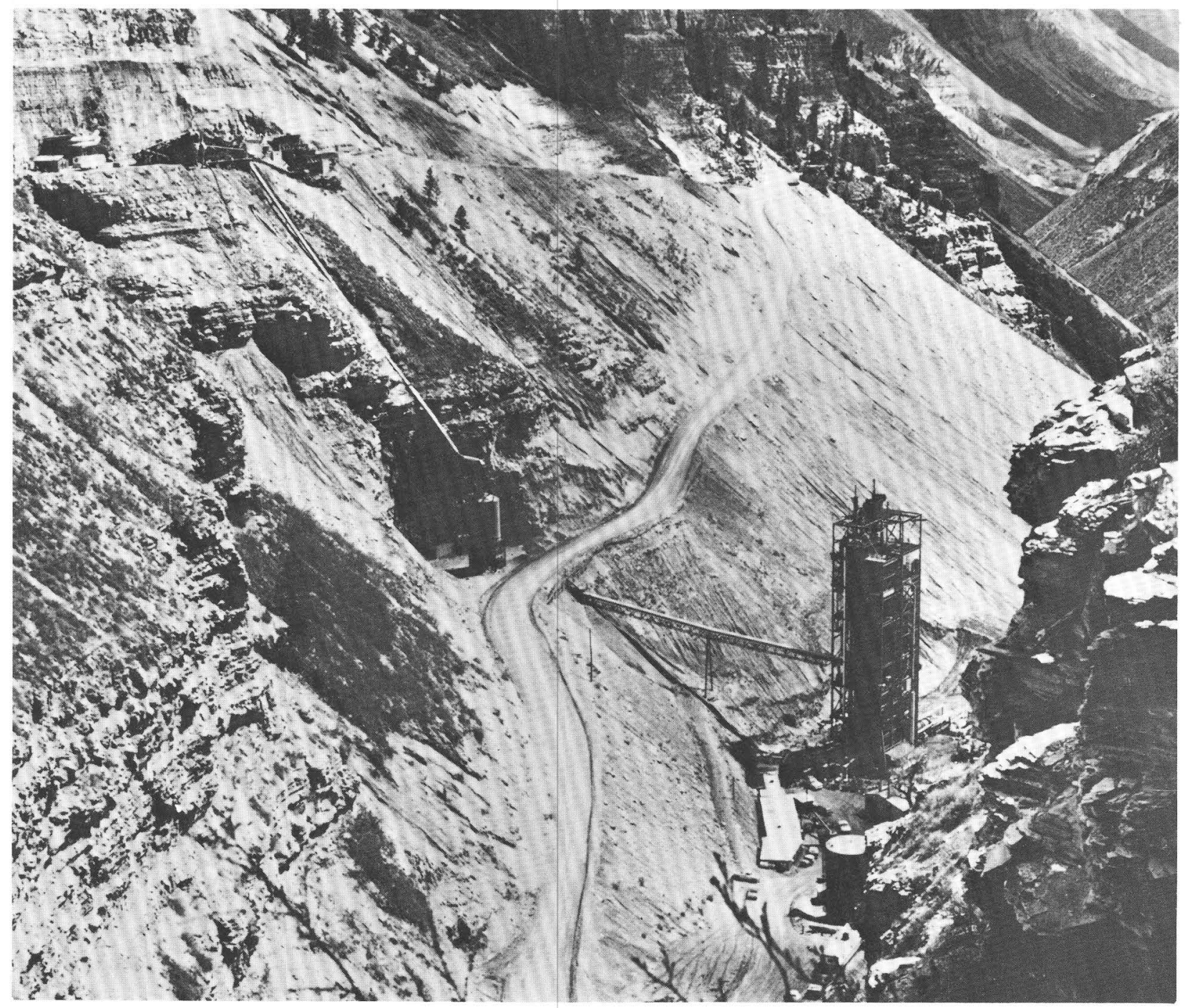

Colony oil shale retort near Parachute, Colo., operated by the Exxon Corporation and The Oil Shale Company. Photograph courtesy of Electric Power Research Institute. 


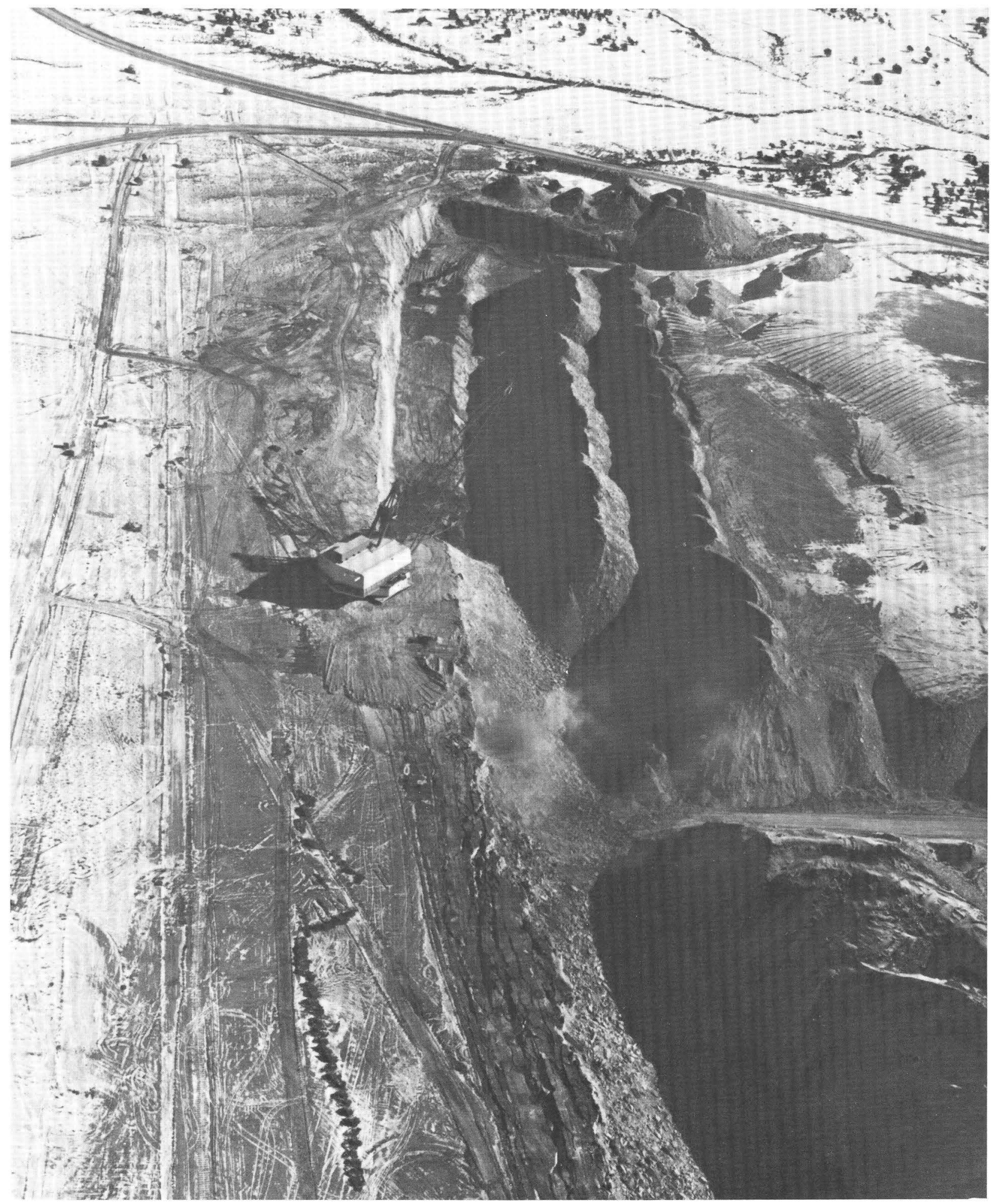

Surface mining of coal at Black Mesa mine in Arizona under the Navajo Project (Power Participation Agreement). Photograph courtesy of U.S. Bureau of Reclamation. 


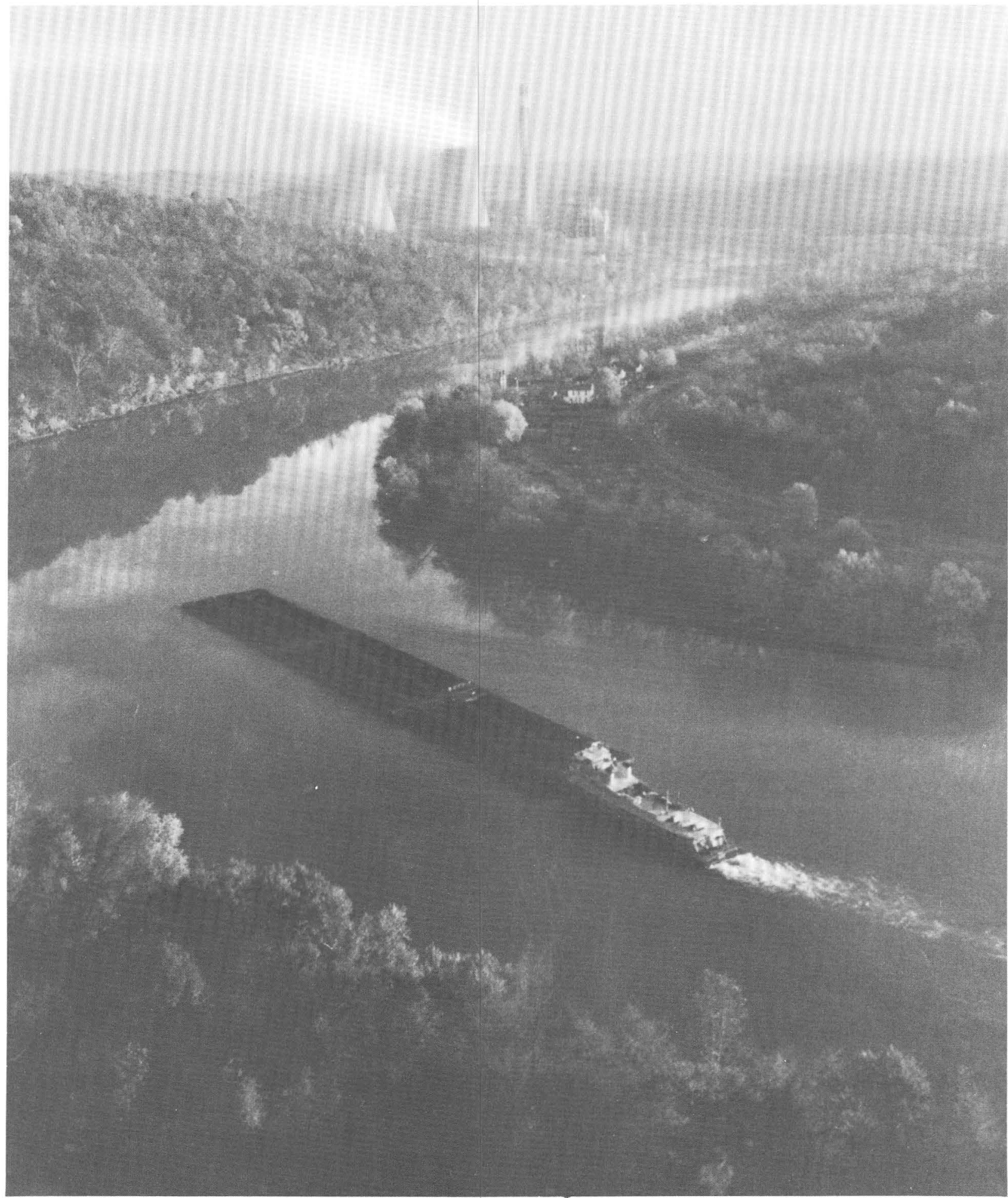

Coal-laden barges on the Monongahela River in southern Pennsylvania, bound for a generating station, shown in the background emitting steam. Photograph courtesy of Conoco, Inc. 


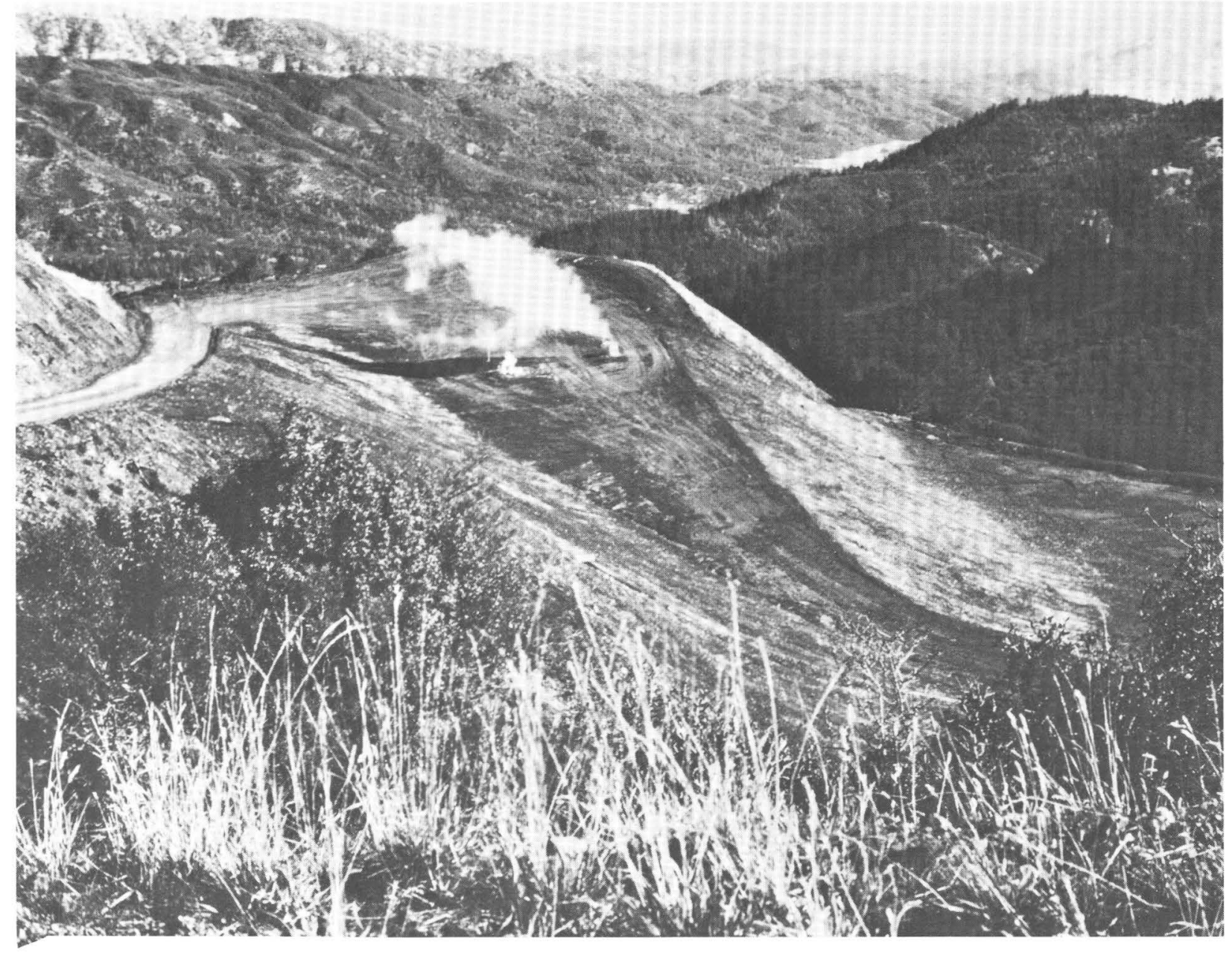

The Geysers geothermal field in northern California, the first geothermal well completed on Federal lands. U.S. Geological Survey photograph.

\section{WATER AND PEOPLE}

Discussion of water at the Symposium concentrated on managing the distribution of available supplies and on the extremes of availability (floods and drought).

Water has always been regarded differently from any other mineral commodity; in one way or another, it is regarded as public property rather than as a freemarket commodity. The economic law of supply and demand is not directly applicable to water, yet it is obvious that the supply and demand relationship has an effect on how it is managed. When it becomes necessary to make decisions about how available water is to be allocated, this responsibility is generally undertaken by the state as trustee for its people. The mechanism for such management varies according to the structure of the state, but it appears that developing nations as well as developed countries are well along the path toward state regulation of water supplies, both for drinking and for irrigation. In some countries, it appears that state regulation will supersede the traditional legal provision that water rights are attached to the land. In other countries, water rights are being separated from land ownership and can be sold separately.

The management of ground water is, in many areas, more difficult than that of surface water because of incomplete knowledge of ground-water occurrence and of the amount of resources. Its use can be regulated by requiring permits for well drilling, limiting the capacity of pumps, limiting the hours of use, or setting a minimum allowable distance between wells. As population density increases, such action by the state becomes necessary.

Especially in highly developed countries, the price of water can vary enormously, depending on its use. Studies made in the United States in 1955 showed that the 


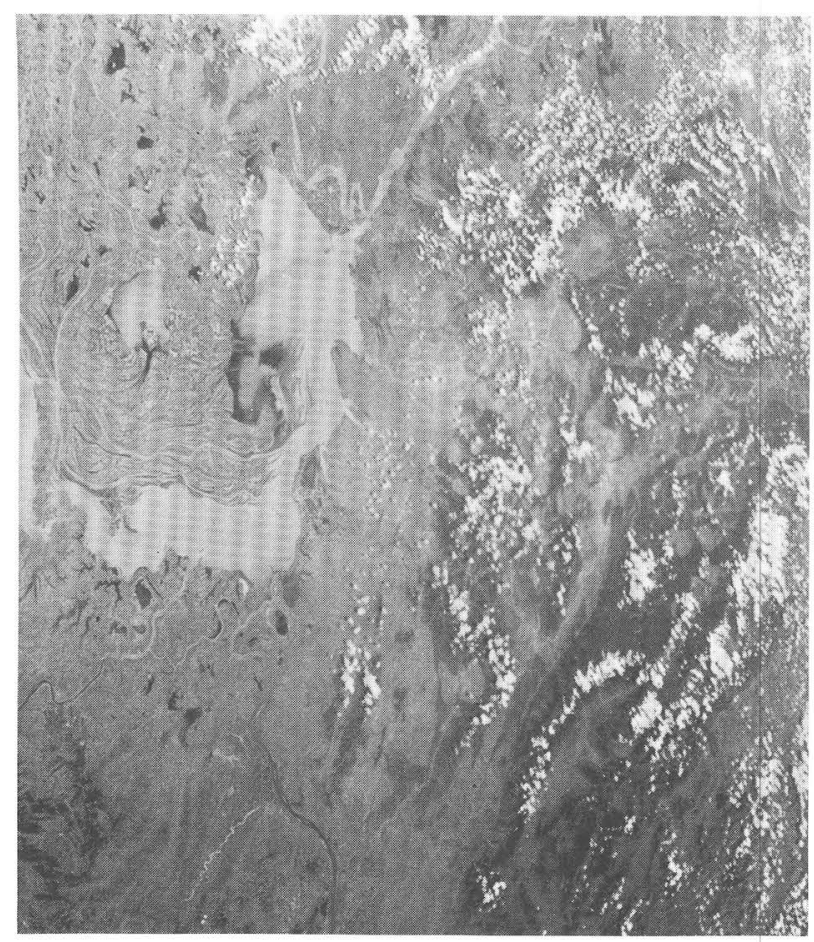

Yangtze River and Tunging Hu Lake in China. Gemini IV photograph 65-HC-792 (here reproduced in black and white). Photograph courtesy of National Aeronautics and Space Administration.

cost of water for domestic use was about $\$ 98 /$ acre-ft. For industrial use, it was about $\$ 8$ or $\$ 8.50 /$ acre-ft and, for irrigation, about $\$ 3 / \mathrm{acre}$-ft; other studies suggested that, for rain-fed cropland, it was about \$1/ acre-ft and, for silviculture, about $\$ 0.24 /$ acre-ft. The values added on to the cost of water for rain-fed cropland are for treatment and transportation of water, but they involve demand also; as an example, the overriding need of the city of Los Angeles for water and the willingness of its citizens to pay higher prices for water for domestic and industrial use have had the effect of diverting water from large rural areas of California where it can no longer be used for agricultural purposes.

To ensure optimum use of water, some areas now resort to regional planning (by river basin or groups of river basins). France, for instance, is divided into eight basin regions. For each region, there are two organizations: a financial agency and a technical agency. $\mathrm{Mu}-$ nicipal representatives and private citizens participate directly in both. Taxes on consumptive and hydroelectric use are applied to construction of treatment works, low-interest loans to municipalities and private industry, and nonreimbursable subsidies. Pollution taxes induce industrial users to treat the water before returning it to the system by exempting from taxation any industry or municipality that does its own treatment. In 8 years, this regional plan has reduced pollution by 50 percent.

In both developed and developing countries, the trend appears to be toward more careful government control of water use, with user participation in the planning process, and toward rethinking the pricing of water as a commodity. If this trend is projected into the 21 st century, it seems possible that a single water law may govern seawater as well as coastal, continental, and atmospheric water. Use of all waters may be in the public domain or under government control. Techniques of water pricing may be improved. The principle of "the polluter pays" may become generalized. Above all, it seems that water policies for a region will have to stress long-term stability based on sustained supplies and productivity rather than on maximum short-term production.

The problem of floods and drought is emphasized by climatologists' prediction that we can expect some decades of more extreme weather. Preparation for such contingencies will differ, of course, in each region or country concerned. Take as an example the southern Canadian prairies, which have low rainfall. Here small water projects have been most effective in combating drought (for example, increasing the depth of farm and community wells, digging farm ponds, and planting shelter belts of drought-resistant trees). Construction of large water projects has been less successful. Some thought has been given to diverting northwardflowing streams to southern Canada. This scheme is now being questioned, however, because it could upset ecosystems and perhaps change the salinity of the Arctic seas by reducing the amount of freshwater discharge, which, in turn, could trigger a major climatic change.

Programs based on the idea of taming nature have usually failed, particularly in the case of floods. Floods, like droughts, are part of a natural cycle; they become disasters only when man has pressed the environment beyond the limits of its ability to support or tolerate him. In coping with the threat of floods, Canada and the United States, among others, are tending more and more toward damage reduction rather than flood reduction. Such programs involve delineating flood plains in populated areas and then taking steps to discourage building on them unless the structures are flood proofed. Zoning is sometimes used by local governments to attain this end, as is the refusal to provide disaster relief for such areas. Where there are existing 


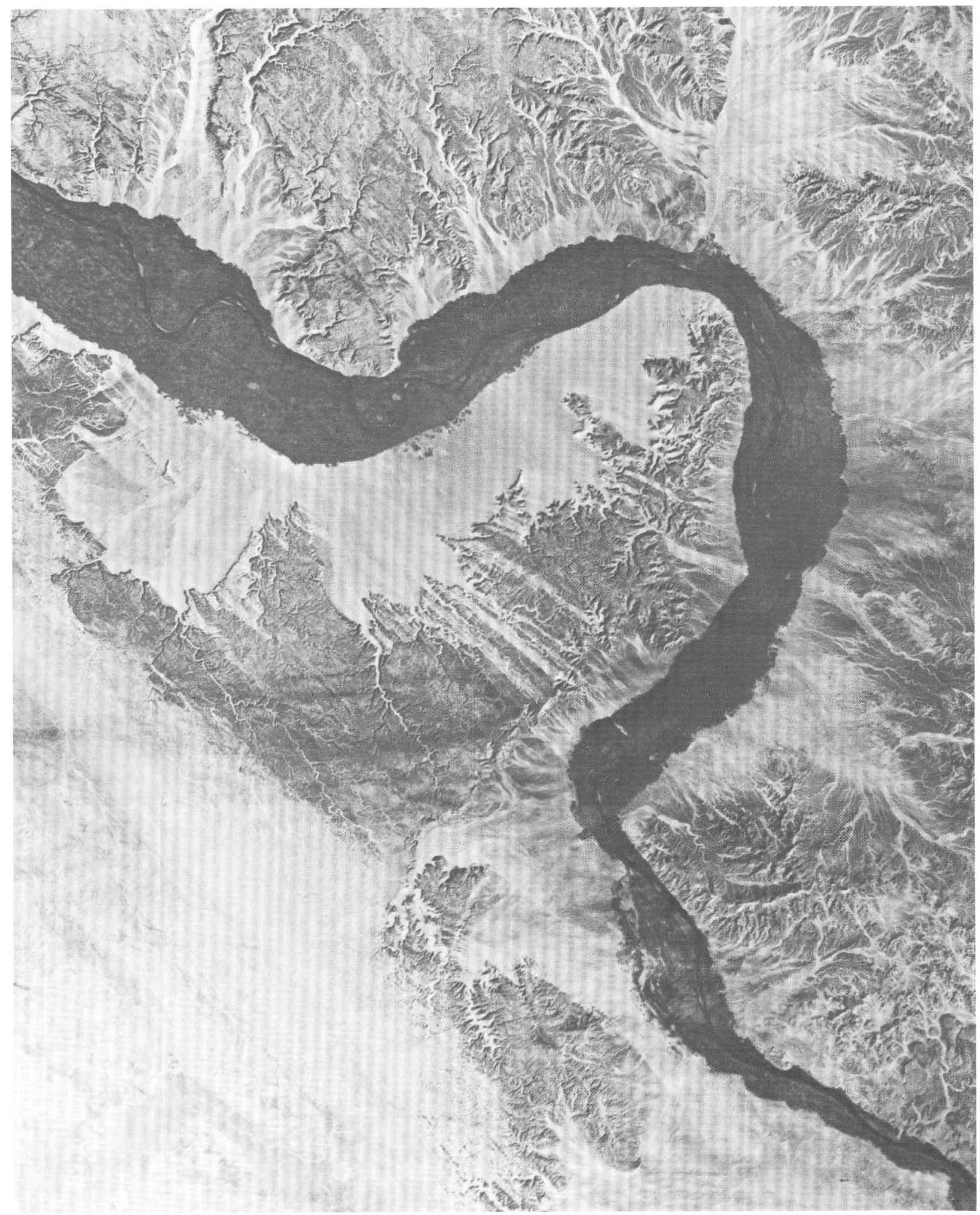

False-color Landsat image (reproduced in black and white) of the area of the Nile around Luxor, Egypt, about $200 \mathrm{~km}$ downstream from the Aswan Dam, where floods have been replaced by perennial irrigation. 


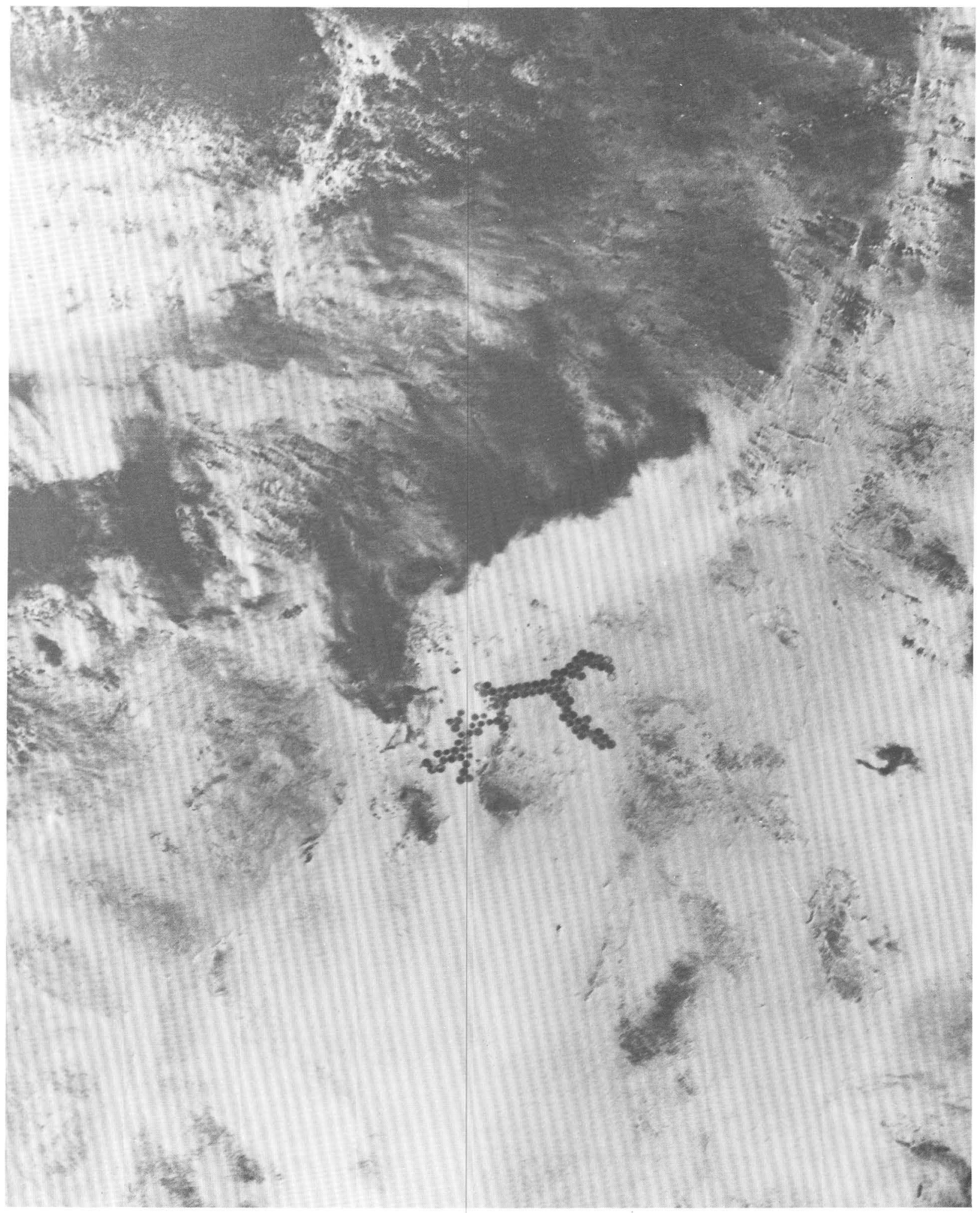

Crops in the Libyan desert. The dots are circular fields of crops grown under center-pivot irrigation near the oases of Kufra. 


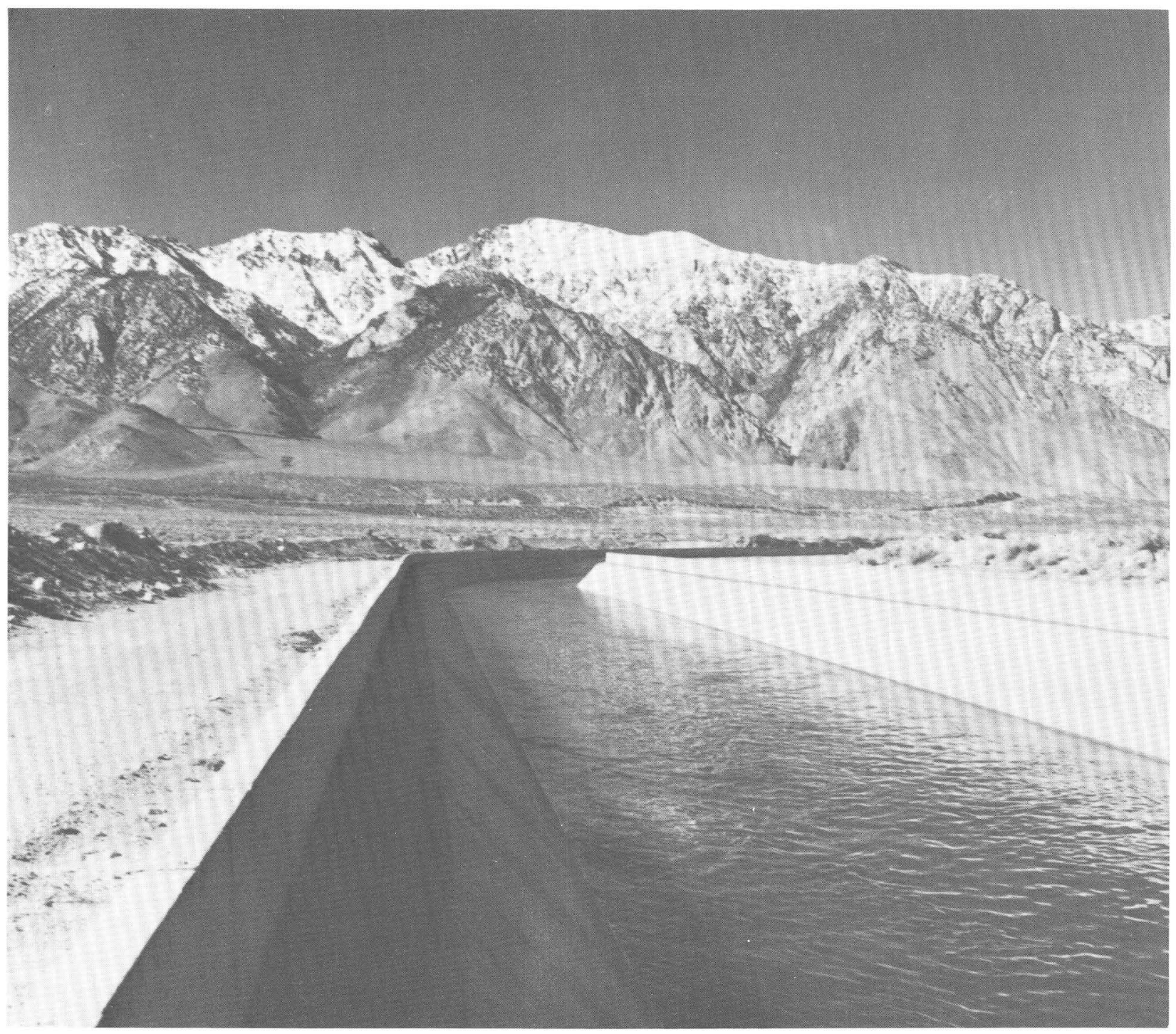

Portion of the Los Angeles Owens River Aqueduct crossing the desert. Photograph courtesy of the City of Los Angeles Department of Power and Water. 


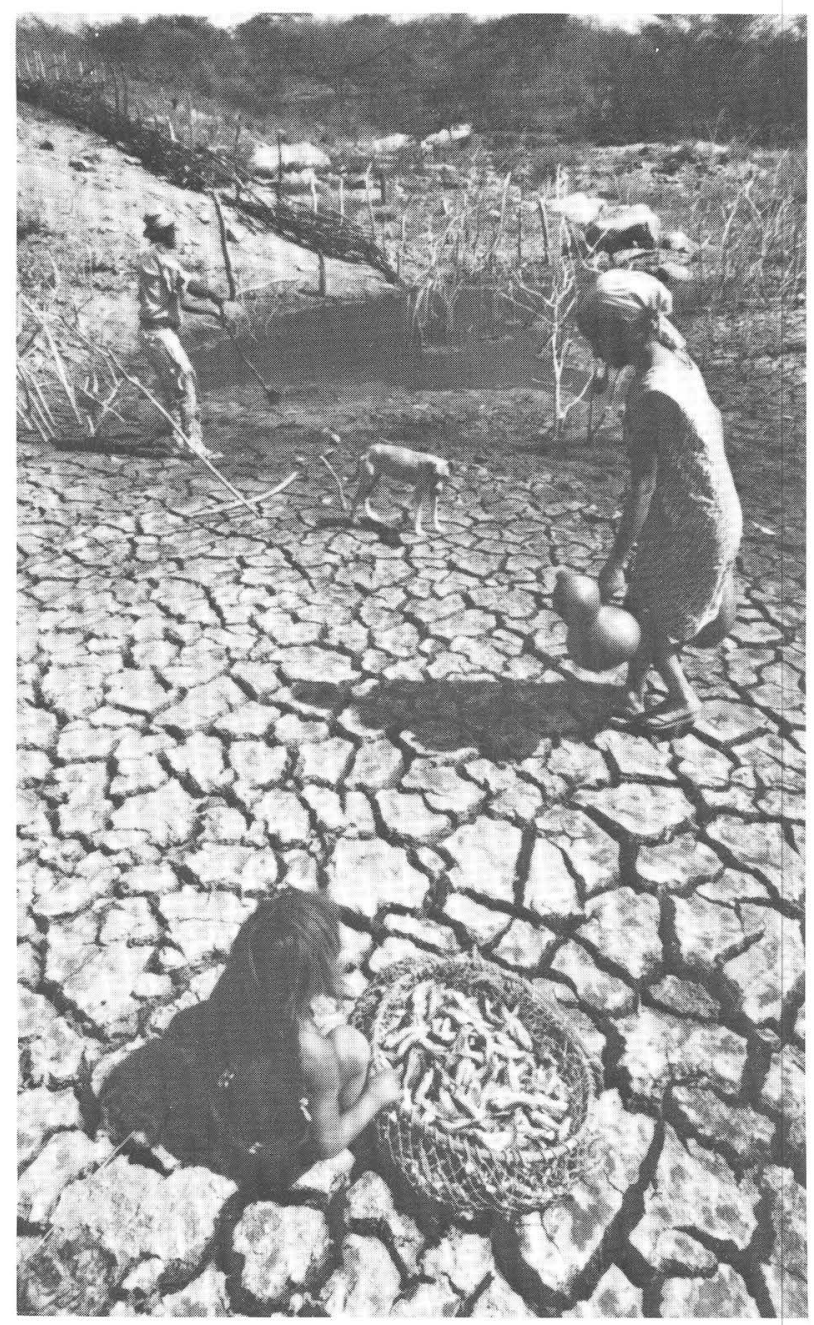

Drought in northeastern Brazil. Photograph by Gordon Gahan, copyright by National Geographic Society.

structures in flood-prone areas, protective diversionary structures are sometimes used.

To manage the water supply and to cope with drought and floods, man's activities, in the long run, must be in balance with nature.

\section{PEOPLE AND THE ENVIRONMENT}

Our environment is our most precious resource, but, until recently, it has been taken for granted. The world is now very much aware of the damage that can be done to the environment, and great efforts are being made to prevent or correct such damage. If recent technical developments are not handled properly, they could increase geologic hazards and result in pollution of the atmosphere, reduction of forests, modification of rivers, lakes, and ground water, and other primary effects. Beyond these effects and resulting from them in ways that we do not fully understand are large secondary or derivative effects such as the modification of climate. The increasing pace of technology, coupled with population growth, accelerates such trends and renders ever more urgent the need to understand and control them.

Much as humans are to blame for the deterioration of their surroundings, certain natural phenomena also pollute and alter the environment and often threaten life itself. Conspicuous among these are volcanic eruptions and earthquakes. Landslides are a damaging and often dangerous phenomenon. Although ground subsidence and expansive soils are not usually dangerous to human life, they can cause great damage to structures. Floods and droughts are widespread and serious threats. The effort to understand and to predict the occurrence of geologic hazards has led to an international cooperation in research that bodes well for the future.

\section{Earthquakes}

The worldwide nature of the earthquake threat has stimulated an improved exchange of information on methods of dealing with earthquakes. The highly successful international research programs now underway are excellent examples of international scientific cooperation. In the last 15 years, a highly effective interdisciplinary approach involving engineers, seismologists, geologists, sociologists, land-use planners, politicians, and financiers has developed. Although we have a long way to go, our confidence in our predictive capability has increased, as has the attention paid by governments to the recommendations of scientists. Such recommendations are not limited to earthquake prediction; more important at the present time, because they are better understood, are preventive measures such as earthquake-resistant design and land-use planning. It was pointed out during the Symposium that, especially in less well developed countries, a simple upgrading of craftsmanship in masonry work would perhaps do more to save lives than all our sophisticated and advanced technology combined.

In the U.S.S.R., seismic zoning, developed since 1930, is the basis for all state planning, design, and building operations. Detailed geologic investigations are required for sensitive projects such as hydrotechnical projects and nuclear power plants. Similar approaches are being developed in other countries.

All prediction and amelioration of earthquake activity must be based on fundamental scientific studies, and international cooperation is paying off in this re- 
gard. As one American worker said, work in Turkey may teach us more about the San Andreas fault than our studies in California will.

An important impetus to the improvement of earthquake prediction is its importance to less well developed countries, where earthquake-proof construction and land-use planning procedures are too expensive to implement. In the Peoples' Republic of China, tens of thousands of lives have been saved by successful earthquake predictions. In the U.S.S.R., several successful predictions have been made. Earthquake studies in California are being bolstered by studies of seismicity in other parts of the United States. Japan, like the Peoples' Republic of China, has had excellent success in recognizing earthquake swarms.

In Japan, the Earthquake Research Institute of the University of Tokyo is working on quantified expression of earthquake prediction, giving a success rate that can then be used in calculating the cost of prediction. The cost of prediction as projected for the next 10 years is still only a fraction of a percent of the property damage caused by the 1923 earthquake. The percentage becomes even smaller when we consider how explosively the potential for disaster has been increased by the growth of urban populations.

As examples of current research programs, earthquake studies in the Andean region of South America and in Turkey were selected for detailed consideration by the Symposium.

A pilot study of Andean seismicity was proposed in 1973 and approved by the Organization of American States. Funds were provided to CERESIS, the Regional Center for Seismology for South America, to carry out the project in Bolivia, Colombia, Ecuador, and Peru and to produce preliminary seismotectonic and seismic risk maps. As the project nears completion, more than 30,000 seismic events occurring between 1471 and 1977 have been identified, and preliminary maps have been produced. Concurrently, scientists from Peru, Colombia, Ecuador, and Bolivia have collaborated with colleagues from France, the United States, and Canada on fundamental research into the nature of tectonic forces, such as analysis of the subduction of the Nazca Plate.

In Peru, the National Civil Defense Committee has appointed a scientific advisory group to evaluate hazard potential. This project includes consideration of landslides, mudflows, subsidence, rockfalls, tsunamis, earthquakes, and volcanoes. Effects of rainfall, electrical storms, freezes, ocean currents, droughts, and pollution and other manmade hazards are also considered.
Turkey has begun earthquake-prediction studies within the framework of a research project sponsored by the U.S. Geological Survey. One of the most seismically active continental regions in the world, Turkey has a 2,000-year historical record of earthquakes. The Turkish program consists of (1) detailed geologic mapping of fault zones, (2) monitoring of microearthquakes, (3) measurement of ground deformation, and (4) assembly of earthquake statistics for risk analysis and for the location of seismic gaps along major fault lines. The most complicated and seismically important part of eastern Turkey has been mapped. Markers have been placed so that the network can be resurveyed to determine changes in the strain field near a plate boundary.

In the search for an understanding of tectonic processes, space technology offers the best way to measure global-scale deformation on such major faults as the North Anatolian fault in Turkey, the San Andreas fault in the United States, and the Alpine fault in New Zealand. The European Space Agency is formulating a plan to make a study of the North Anatolian fault, and the Andean countries are discussing with the $\mathrm{Na}$ tional Aeronautics and Space Administration the possibility of participating in NASA's Geodynamics Program.

In earthquake studies, continuity is necessary, and international cooperation is important.

\section{Volcanoes}

As it has in earthquake studies, international cooperation in the study of volcanoes has greatly increased in recent years, again with the aim of being able to predict events. In discussions at the Symposium, two aspects of volcano studies emerged-adequacy of baseline geophysical data and the relationship between scientists and the public.

In terms of human safety, the critical decision in a period of volcanic activity is when to order evacuation of an area. The chances of correctly predicting an eruption are greatly increased by baseline observations, such as those provided by a network of seismometers documenting upward movement of earthquake foci or by deformation studies designed to detect changes in the shape of a volcano.

Two recent eruptions in the eastern Caribbean exemplify the need for baseline data. In 1976, eruptions of steam and ash from La Soufrière volcano on the island of Guadeloupe, accompanied by hundreds of local earthquakes, seemed to presage a dangerous eruption. Tens of thousands of people were evacuated from the area for a period of several months. The 


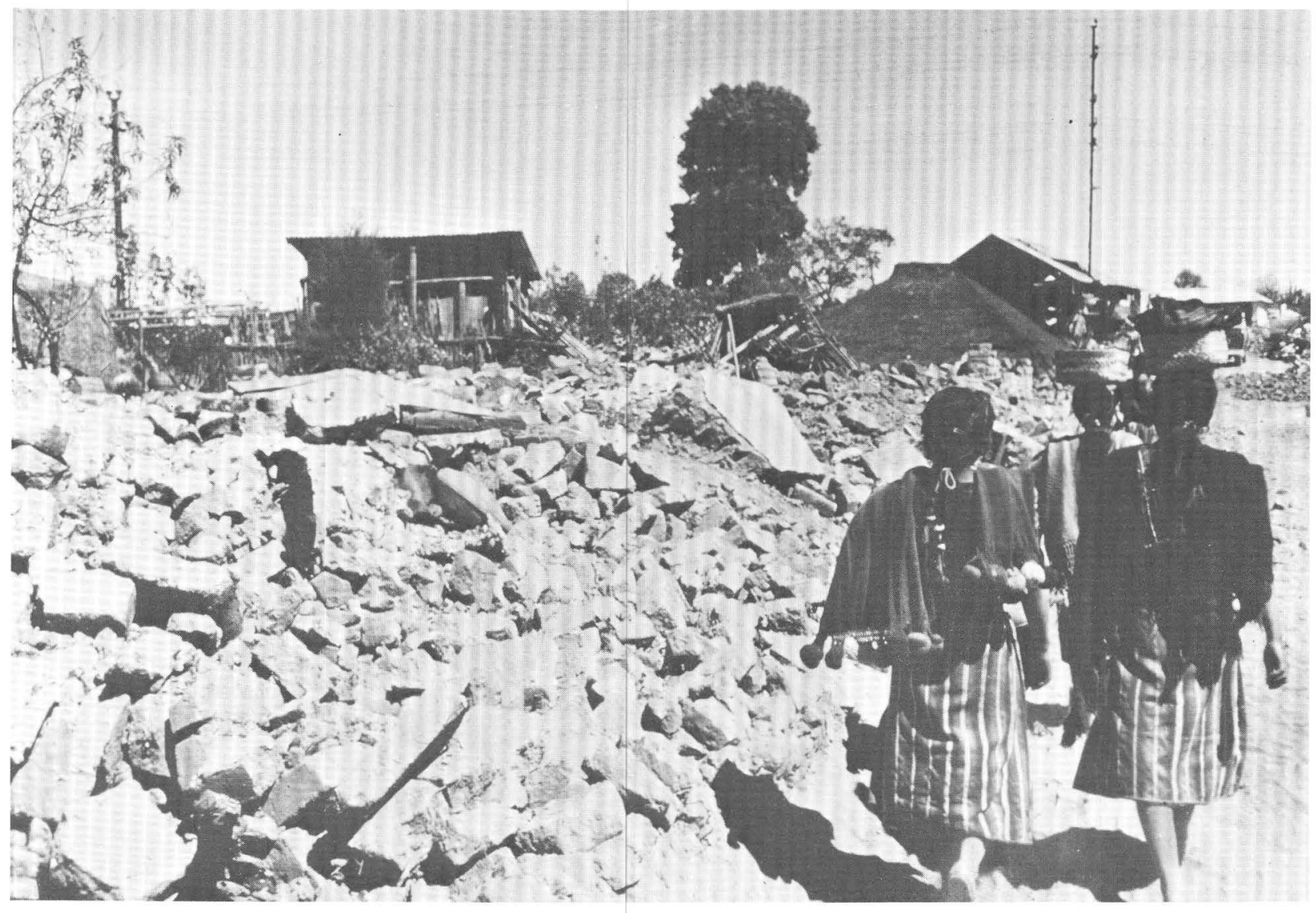

Poverty accents geologic disasters. When this village was struck by the 1976 Guatemalan earthquake, 100 percent of its adobe structures were destroyed. Photograph by Samuel Bonis.

eruption never occurred. During the long period of evacuation, scientists and authorities were uncertain about the significance of the volcanic events. In great part, this uncertainty was due to a lack of baseline data; knowledge of long-term changes in the volcano could have led to an estimate of the time of an eruption and of what type of eruption might take place.

In 1979, another Caribbean eruption occurred on the island of St. Vincent. This volcano, also named Soufrière, had, by contrast, been subjected to baseline geophysical studies. The temperature of the water in the crater lake had been monitored at regular intervals and found to be increasing. Tiltmeters installed 2 years before the eruption indicated that the volcano was swelling. Seismometers were in operation on and near the volcano. When the eruption came, it was so sudden that evacuation was immediate. But the baseline data were valuable in interpreting the course of volcanic activity after the first eruption and thus helped to determine when it would be safe to return the evacuees to their homes.
Coping with volcanic activity requires the combined efforts of scientists, engineers, and political authorities. In addition, the news media play a very important part in conveying information to the populace. The two Caribbean eruptions furnished contrasting examples of press relations. On Guadeloupe, the press corps was allowed almost unlimited access to the volcanologists, some of whom were in disagreement concerning interpretation of the observed phenomena. Thus, at times, the disagreements, rather than what was happening at the volcano, became the news. In St. Vincent, on the other hand, the press was briefed by government representatives, who used information supplied by the scientists.

Informing the public concerning volcanic activity on a small island is, of course, far simpler than it would be in a large area such as the Western United States. The eruption of Mount St. Helens, which began several months after the International Centennial Symposium, exemplifies the need for dissemination of timely and accurate information and shows how it can be 
done on a large scale. The frequent release of up-todate information was handled by a staff of information officers working with the scientists. The scientists were available for press briefings as their work permitted; the information officers served as a continuing source of information.

Releasing information to the public is difficult because we do not know how best to help the public understand natural hazards, particularly when the inadequate state of our knowledge leads to uncertainty about the timing and course of hazardous events. Hence, it is encouraging that sociologists are making studies of people's response to news. These studies may lead to more effective policies concerning the timing and the manner in which possible impending hazards are announced and the best ways to impart the incomplete state of our scientific knowledge.

\section{Understanding and guiding man's influence on the environment}

Since World War II, there has been a rapidly growing awareness, especially in developed countries, of man's degradational effect upon his environment deforestation and consequent depletion of the soil; air and water pollution; loss of topsoil through erosion; silting of rivers and harbors; alteration of the microclimate in large cities; and many other results of the world's growing population pressure. Although such phenomena are less spectacular than earthquakes or volcanoes, their effects will be far more widespread. We face the problem of trying to stop or reverse these trends where possible, but we must also learn how to avoid them in parts of the world that have not yet been affected and how to plan for the intelligent use of land. In a number of developed and developing countries,

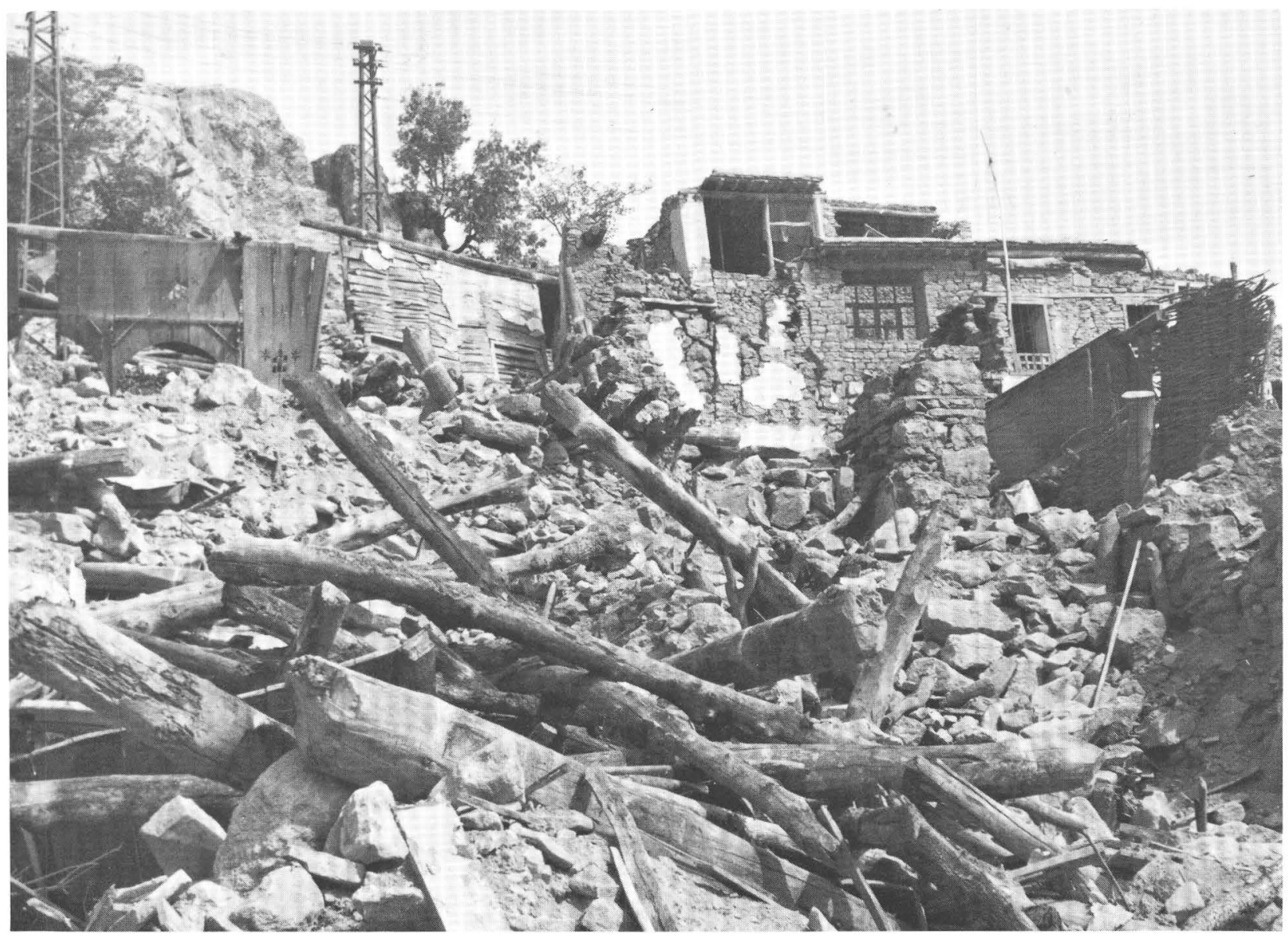

A totally collapsed house in Lice, Turkey, after the earthquake of September 6, 1975. 


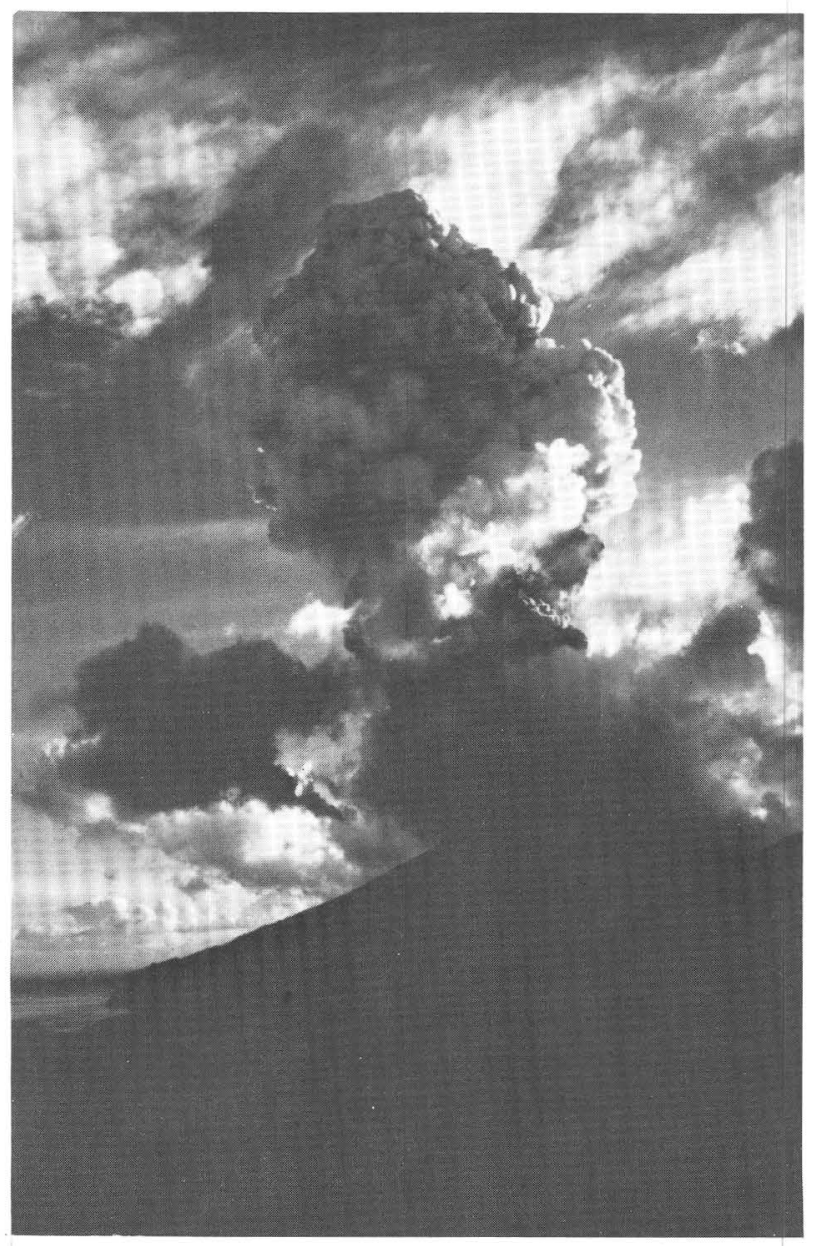

Vertical eruption cloud rising about $5 \mathrm{~km}$ above the summit of Soufrière volcano on the island of St. Vincent in the Caribbean on April 22, 1979. Photograph by Richard S. Fiske.

this concern has led to extensive programs of land analysis using multidisciplinary studies by teams of geologists, soil scientists, foresters, botanists, ecologists, meteorologists, engineers, and representatives of other specialties. Modern remote-sensing technology has made it possible to carry out such surveys on a scale and at a speed that would have been impossible a generation ago. The use of computers, for example, makes it possible to map at generalized levels but to retrieve detailed basic data when they are needed.

Simply put, land analysis is based on landscape mapping - the delineation of units that have similar geneses and that can be described similarly in terms of topography, soil, vegetation, and climate. When these processes have been carried out, the land-use potential of a given landscape unit can be defined without detailed surveying of the entire unit. Such an approach offers great possibilities for both government and pri- vate enterprise to determine the optimum use of the land.

In Australia, such land analysis, called the landsystem approach, has been underway for more than 30 years. The Australian system is also coming into use in Africa, Asia, and parts of South America. The Geological Survey of India's environmental studies began in 1970 with land-use mapping through the use of aerial photographs, Earth satellite imagery, and topographic maps. The first maps resulting from a regional multidisciplinary study, "Operation Anantapur," were released for the first time at the International Centennial Symposium. Along with basic-data maps (geologic, geomorphologic, hydrogeologic, soils, geotechnical, and mineral-resources maps), regional land-use maps serve as a guide for environmental management. Urban studies are also being undertaken in India, and dialogs with state governments are leading to gradual acceptance of suggestions and their incorporation in regional plans.

In the United States, the U.S. Geological Survey established its Land Information and Analysis Office in 1975 to evaluate alternative uses of the land and to provide a sound basis for decisions and land use. This activity was the result of a growing concern in the U.S. Geological Survey with analysis of the land in terms of its potential use, expressed in language understandable by the nongeologist. The first such work (then called "terrain analysis") was done for military purposes during World War II. After the war, the same approach was used to supply data for civil engineering operations, the emphasis being on urban areas. The U.S. Geological Survey's new Office of Earth Sciences Applications has greatly expanded the scope of the work by making extensive use of remote sensing and determining the environmental impact of exploration, development, and production of mineral and energy resources from the public lands.

When the future of land analysis is considered, two problems emerge. The first is the extension of such studies to developing countries. Understandably, the major concern to date with human impact on the environment has been in developed countries, where that impact has been greatest. But, if we are to avoid repeating the mistakes of the past, it is imperative that land analyses be made in areas where development has not begun or is in its early stages. Although land analysis is valuable - indeed, indispensable - it is expensive and requires highly trained personnel. Financing and carrying out such work will require international cooperation and, in some cases, financial aid from international agencies. 


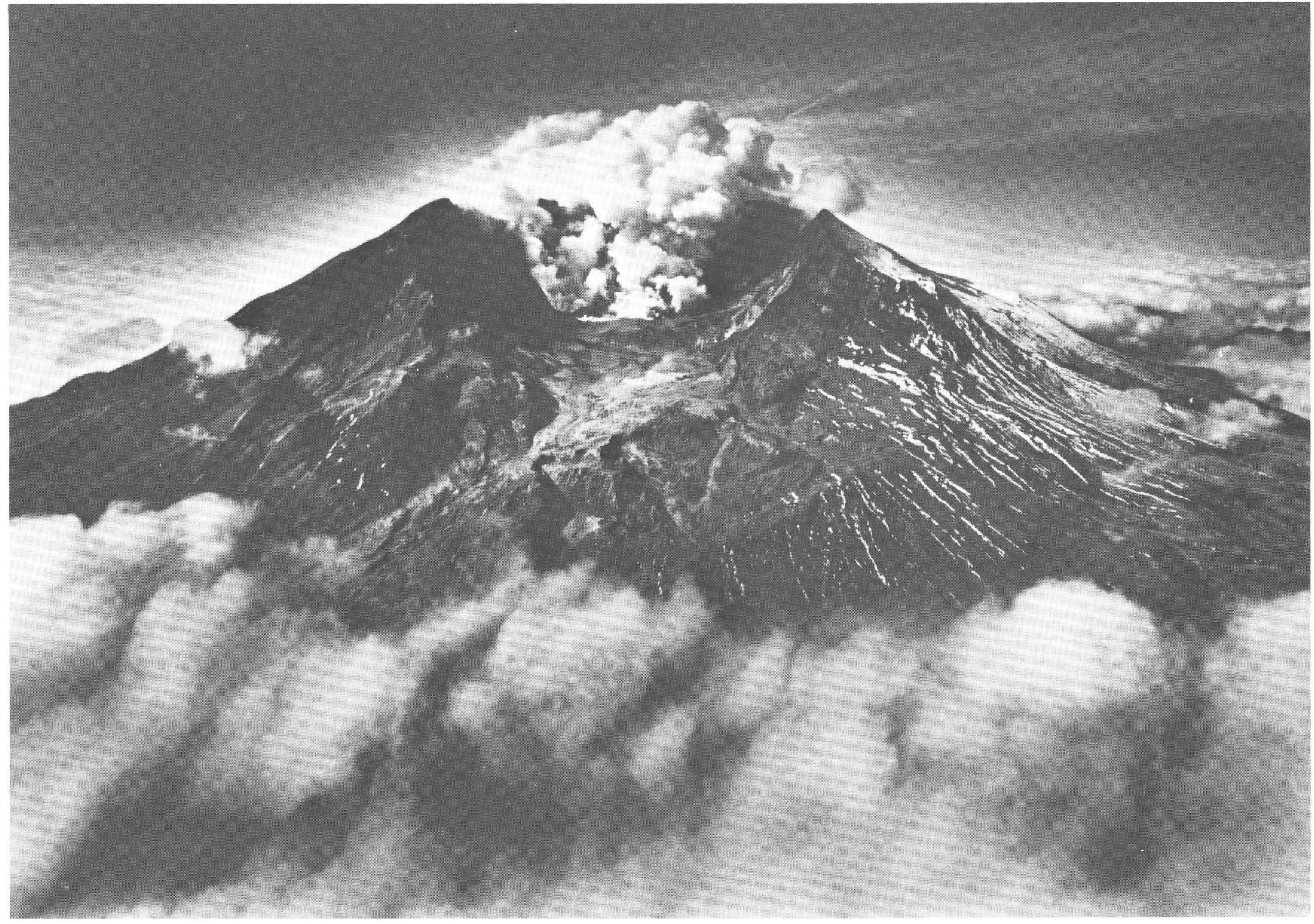

Mount St. Helens in Washington State, May 1980. U.S. Geological Survey photograph. 


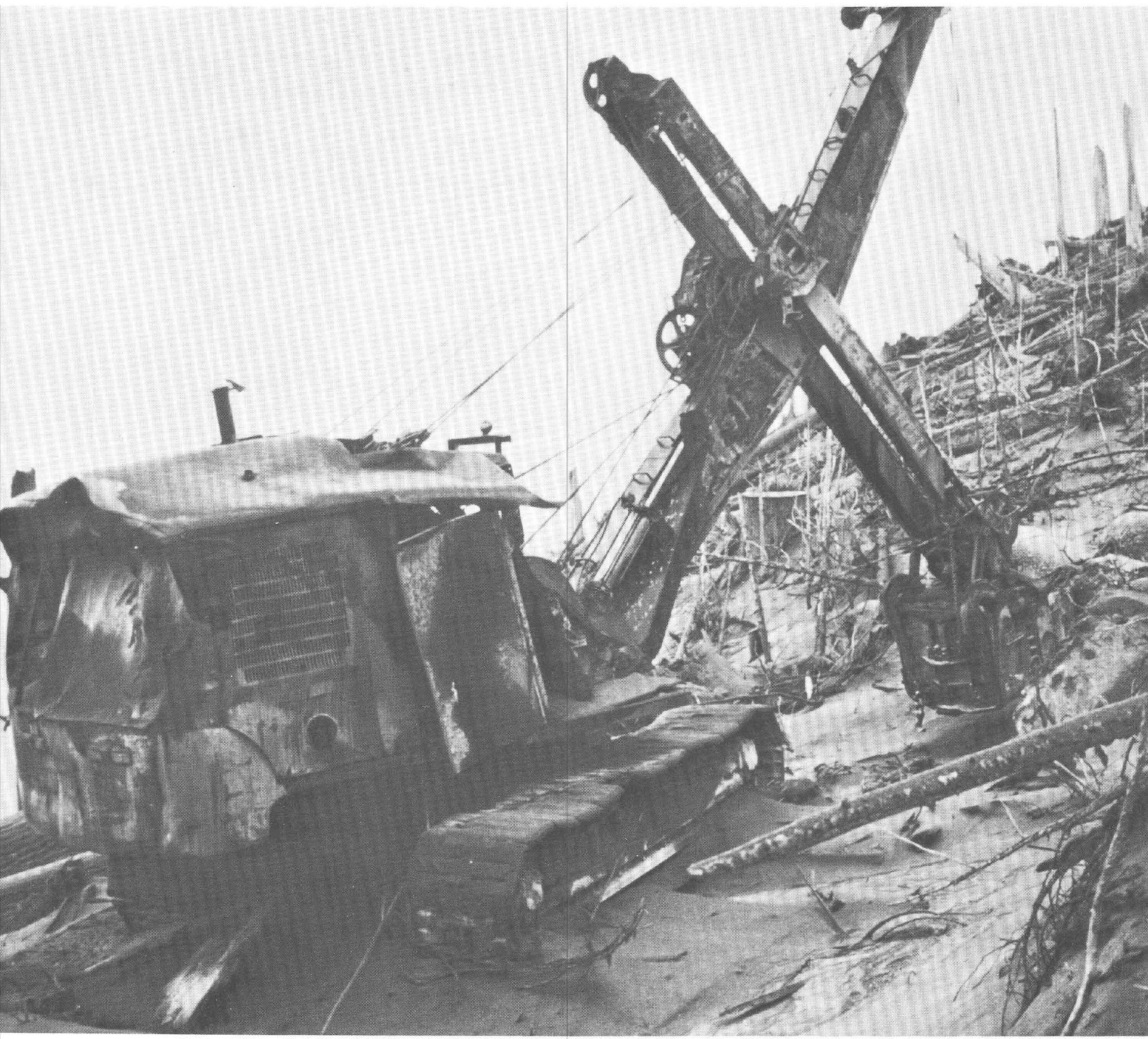

Devastation at the Spud Mountain equipment site on June 5, 1980, following the eruption of Mount St. Helens. U.S. Geological Survey photograph. 


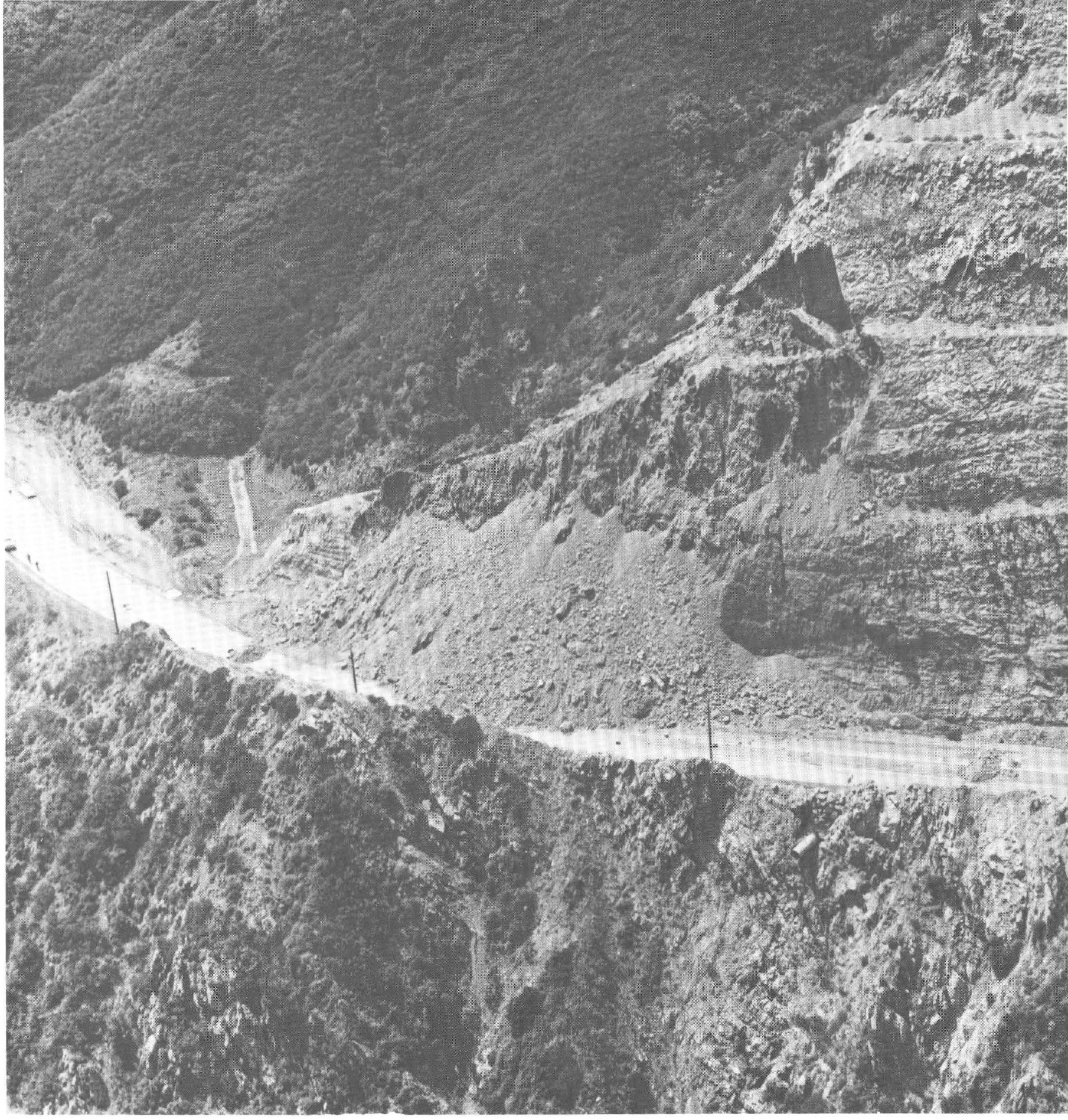

A rock topple and fall halted traffic on this highway in the central Santa Monica Mountains of southern California. Photograph courtesy of the Department of the County Engineer, Los Angeles County, California. 


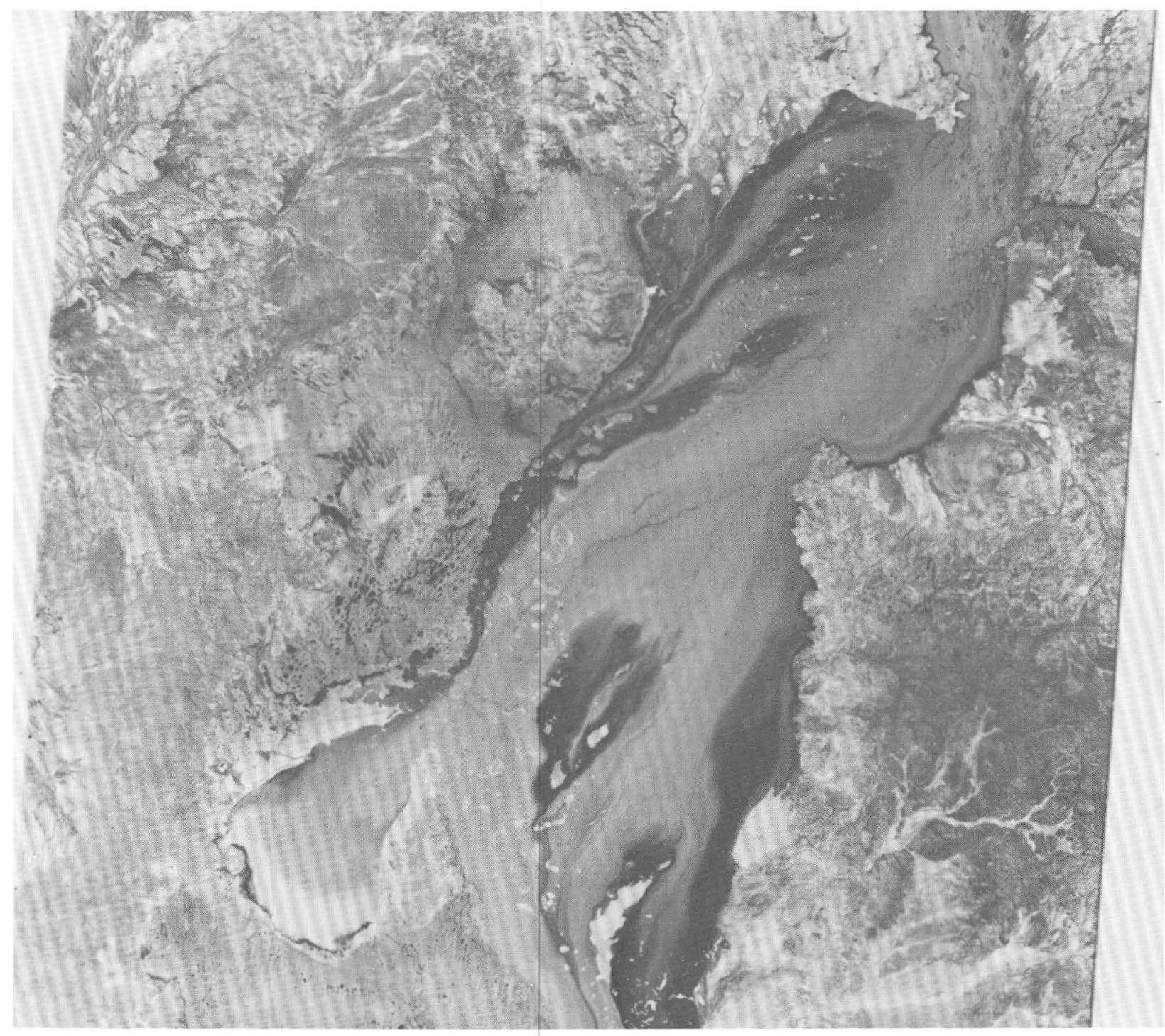

Cooper Creek in Queensland, Australia. Landsat image 1563-23530 shows the creek in flood during the wet season (February 6,1974 ). The original false-color image (here reproduced in black and white) was used to classify terrain types on the basis of vegetation and topography by C. J. Robinove (U.S. Geological Survey Professional Paper 1102, 1979).

The second problem related to land surveys is translating data into action. The products of these new surveys - mostly maps - are being designed for use by nontechnical people, the goal being intelligent land use. Therefore, the most important users of these maps will be government officials who make decisions on issues such as zoning that determine how the land is to be used. In Victoria, Australia, for instance, landanalysis data have been applied directly to state landuse planning and to surveying of grazing and livestock lands to determine safe carrying capacities and management programs. To some extent, the very existence of land-analysis data may lead to their application; but it was the consensus of this Symposium that government decisionmakers generally are not sufficiently aware of the land-analysis information available to them or of the importance of developing such information if it is not available. How to bring such information to the attention of those at the decisionmaking level is one of the major problems facing earth scientists.

\section{NEW MAPS FOR THE WORLD}

From ground surveys to satellites, new techniques have revolutionized mapping in recent years. Surveying instruments in the field can now transmit data to a 


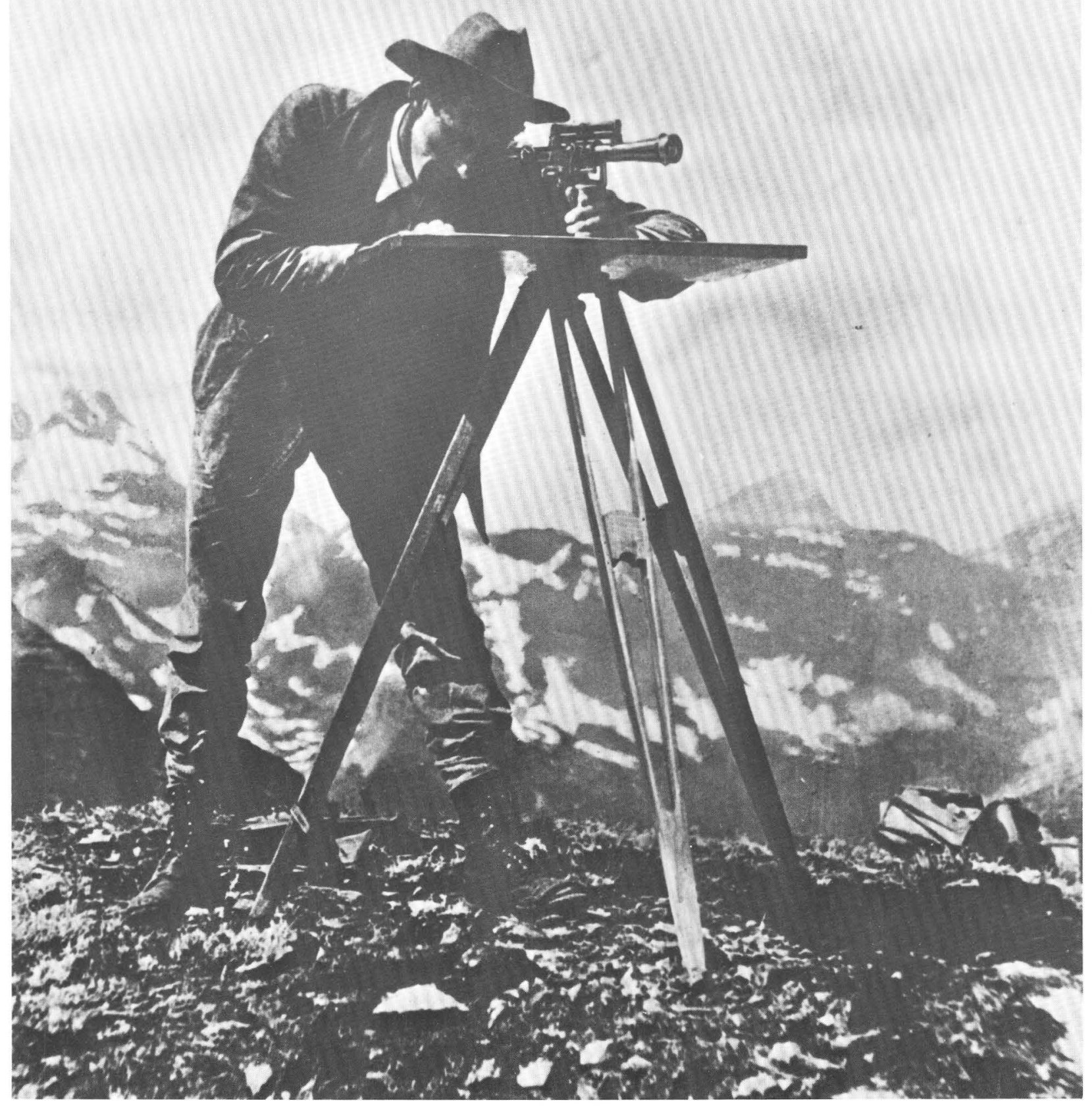

U.S. Geological Survey topographer surveying the Idaho-Montana boundary line in the late 19th century. U.S. Geological Survey photograph. 


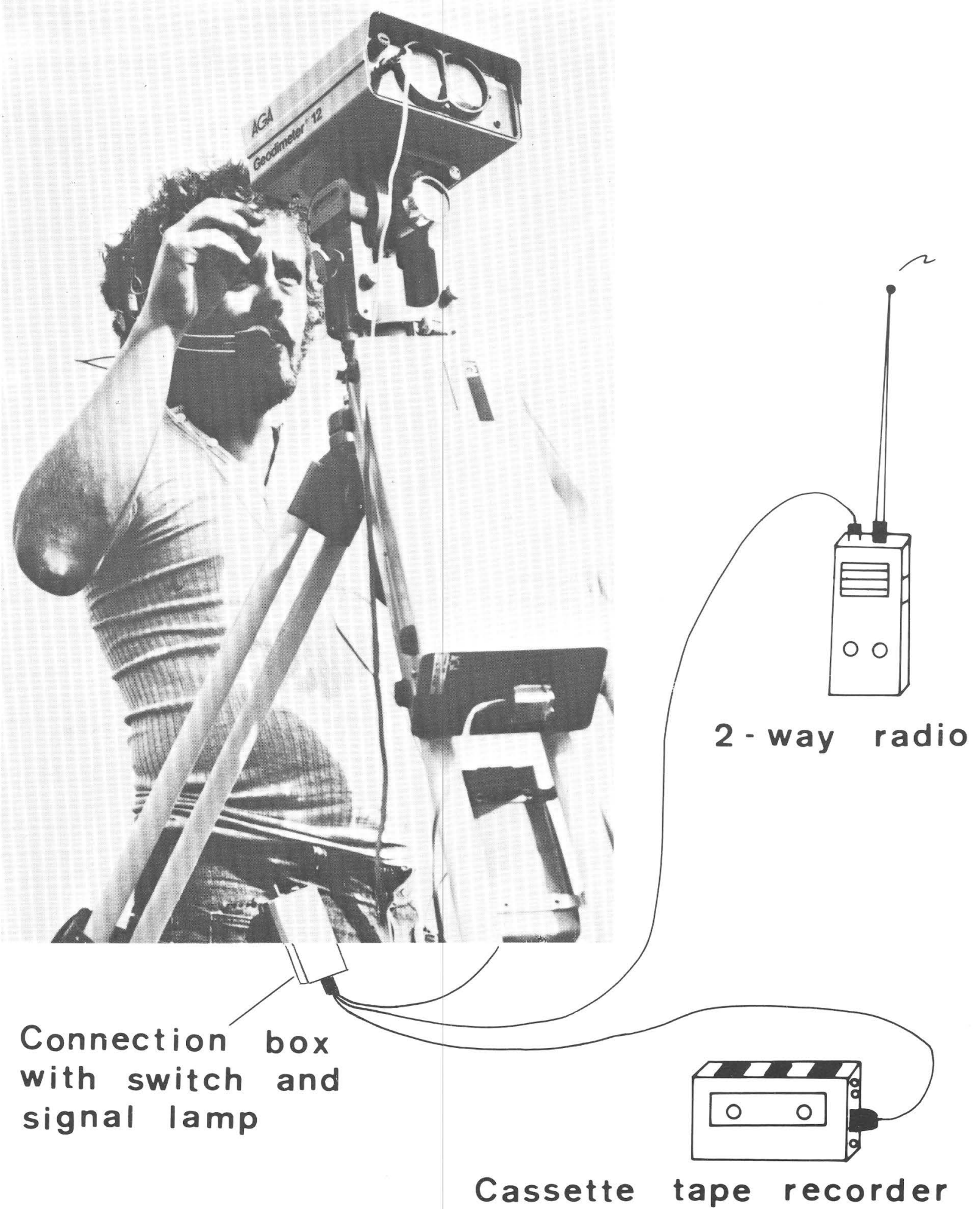

Surveyor in Sweden using remote-recording system. Illustration courtesy of Carl Tenryd. 
calculator in the office so that, before the surveyor leaves his station, the completeness and quality of his survey data can be controlled. This development and others reduce the potential for human error in surveying techniques.

In the field of photogrammetry, we have entered the era of analytical plotters; automation of the photogrammetric process includes storage of data, editing, and film plotting, all through computer techniques. Human assistance is required mainly for correcting the final draft map. In the last few years, the accuracy of photogrammetric techniques has increased, and the quality of modern cameras has improved, so that it is now possible to compile more accurate large-scale maps from much smaller scale photographic images. Digitized information offers a powerful supplement or alternative to film photography.

The most striking innovation in mapping is the satellite data system, which had its beginnings only in 1957, when Sputnik was launched by the U.S.S.R. Now the satellite programs of the United States and of the European Space Agency furnish worldwide data on weather, topography, geology, vegetation, water, soil, population, and many other subjects. Satellite imagery from photogrammetric cameras offers a promising means of rapid mapping if resolution and geometric accuracy requirements can be met.

Yet, despite a quantum jump in mapping efficiency, the world is nowhere near satisfactorily mapped. At medium scales $(1: 50,000$ to $1: 100,000)$, only 30 percent of the world has been mapped. At smaller scales ( $1: 250,000$ to $1: 500,000$ ), map coverage is 65 percent. Not all of this coverage is accurate or complete enough for modern use. As would be expected, the most complete coverage is in the developed countries, the developing countries being very poorly covered.

The great expense of modern cartographic equipment is beyond the means of many developing countries; in some of these countries, national map series are still being produced by plane-table survey, which has the advantage of offering employment to many people. Automated mapping uses fewer people but requires a high degree of technical training.

Whichever type of mapping a country chooses, it is imperative for its development that a continuing mapping program be supported. In some countries, mapping is carried out only in support of specific projects, such as construction schemes. Thus, the general development of the country may be delayed, for mapping is not begun until the specific project has been decided upon, and then it supports only that project. Good planning and wise development require good information about the land and its resources.

\section{THE DEVELOPING COUNTRIES IN A CHANGING WORLD}

Looking to the 21 st century, many developing countries have seemingly bright futures, for they contain within their borders a significant percentage of the Earth's untapped mineral resources. But this prospect is of little comfort today, when many potentially rich nations are inhabited by people who exist at the poverty level. The natural resources of such countries can be developed only on a long-range, systematic basis, yet their immediate problems are so great and their financial resources so meagre that long-range planning must seem an almost insuperable task.

In a poor country, natural hazards loom larger than they do in a rich one because the people live so near the survival level. Floods, droughts, earthquakes, and volcanic eruptions take a greater toll of those who have little food even in normal times and who live in structures that can stand little of nature's stress. When catastrophes strike, the immediate resources of the nation are strained, even when foreign aid is supplied.

Against this background of poverty, the state must decide how best to allocate its resources. In most developing countries, the greatest immediately available resource is people; this availability constitutes an argument in favor of labor-intensive activities, such as the operation of small mines, for the immediate future. As an essential part of a long-range resource-development program, a nation must assure itself a supply of competent technical people such as geologists, hydrologists, engineers, and foresters. Such specialists are in very short supply in developing countries, so training must have high priority in any country's program. In order to develop the nation's mineral and water resources, emphasis should be placed on training field scientists and on giving them incentives, such as adequate per diem payments, that will keep them in the field. Training in foreign countries and working in one's own country with visiting foreign scientists are essential parts of such a program. Geologic and topographic mapping can be carried on at low cost (for jeeps, field per diem, and simple field equipment) and can build an invaluable corps of trained and experienced earth scientists. It is incumbent upon the government to use such scientists as a valuable resource that will contribute, by giving their advice, to the development of their country. 


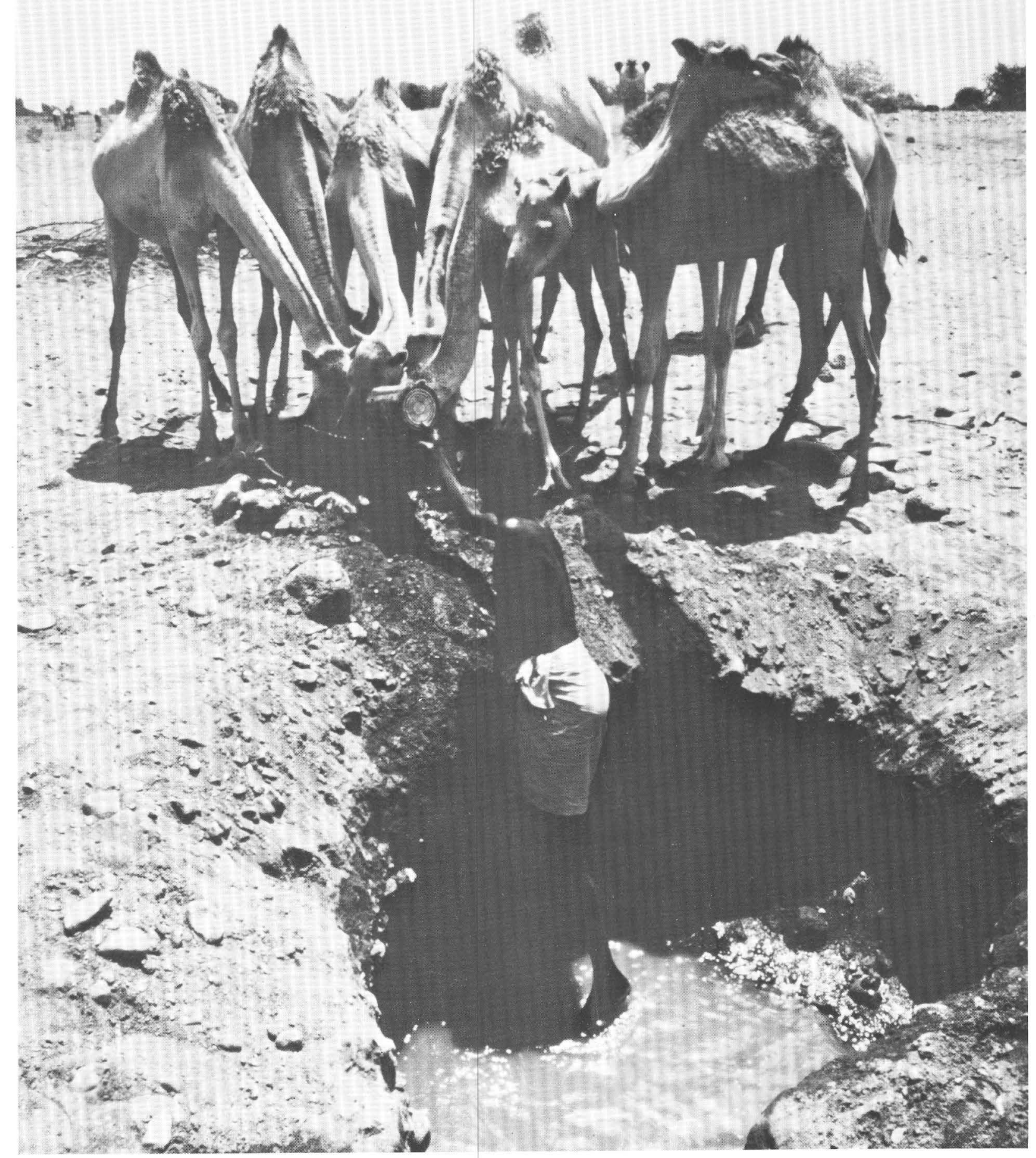

Watering camels in Djibouti. Photograph by Marion Kaplan, copyright by National Geographic Society. 


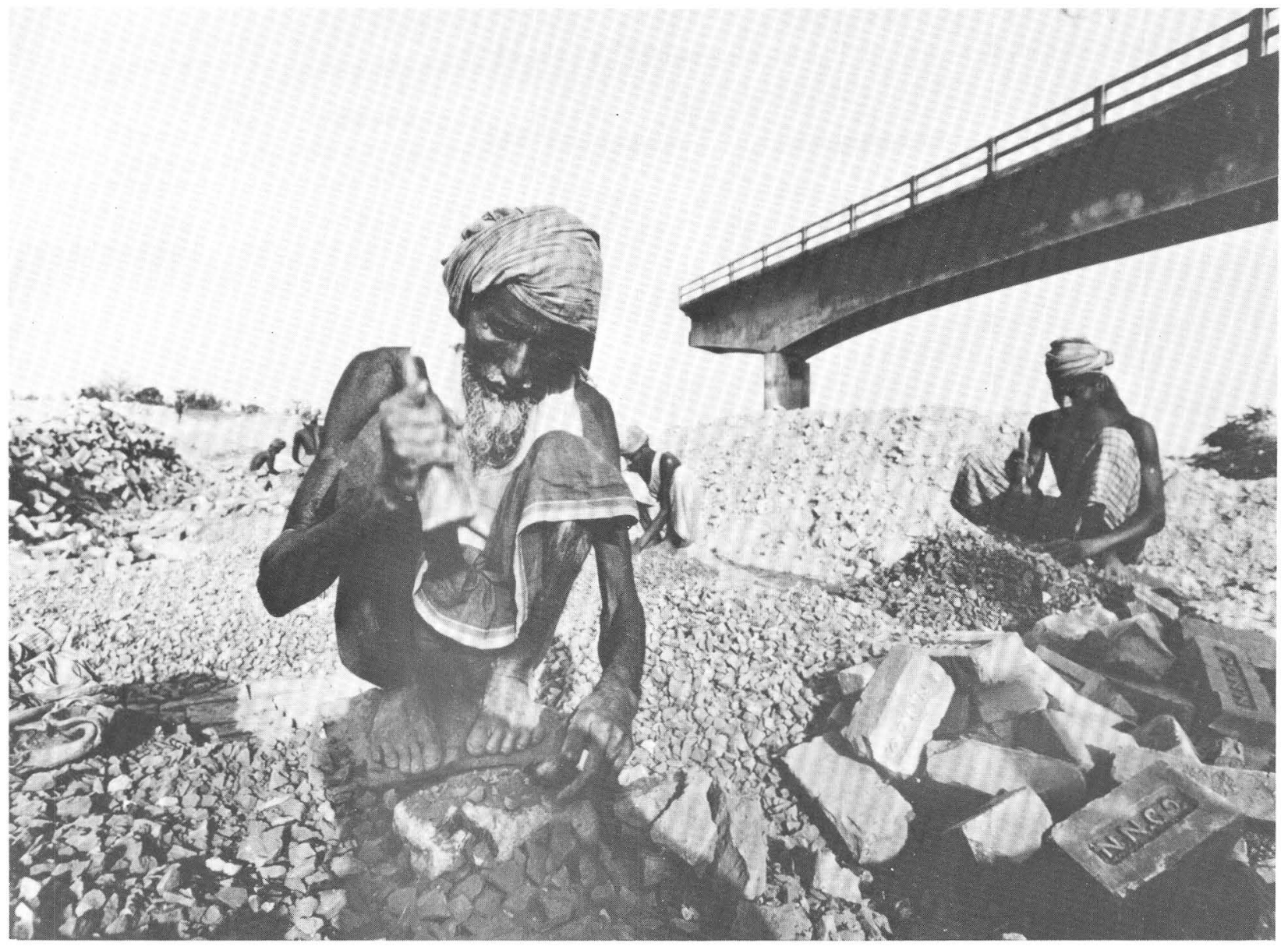

Laborers near Mirzapur in Bangladesh breaking bricks to make road metal. Photograph by Dick Durrance II, copyright by National Geographic Society.

In addition to depending on help from developed nations to train adequate numbers of their own earth scientists, developing nations can do much in cooperation with each other. As an example, the Association of Geologists for International Development has proposed the formation of an International Geoscience Research Institute for the development of mineralexploration techniques in tropical rain-forest regions.

To supplement the resources of the state, the United Nations revolving fund and World Bank funds are becoming more easily available and may soon herald a new era of more direct state participation in mineralexploration efforts. This trend will intensify as the necessity to explore for and mine remote and low-grade deposits increases; these operations will require a large capital outlay before there is any prospect of monetary return.

For countries whose mineral resources are known, ready for development, and needed on the world market, the situation is far different than it was a generation ago. Developing countries have become increasingly aware that their natural resources constitute a major part of their national heritage, to be husbanded and wisely used for the benefit of the nation. Many such countries are now in an awkward transitional state between foreign exploitation and selfsufficiency in developing their natural resources. Economic nationalism in developing countries has led to reluctance on the part of potential investors to engage in new operations. Doubt concerning the political stability of a country can increase this reluctance. Understanding on both sides is, of course, essential in this transitional period. In the immediate future, developing countries will need technical assistance as well as financial help. As an example, it is to the advantage of both the seller and the buyer to process raw materials in the most efficient manner; here, developed countries can make mineral export more attractive to developing countries by supplying them with the advanced technology necessary for such processing. To a growing 
extent, producing nations may require domestic processing of raw materials, which increases local employment and training of nationals and insures maximum utilization of domestically produced goods and services, in addition to increasing the value of their exports.

Estimates of future resource availability are perforce based on present methods of exploration and analysis. These, too, will change, and new techniques already promise to reveal previously unknown resources at depth, both below the land and under the sea bottom. In the last few years, equipment that can explore with reflected sound waves to a depth of 30 to $70 \mathrm{~km}$ has been developed. This equipment has identified new areas for petroleum exploration in previously undetected sedimentary strata beneath crystalline rocks in both the Eastern and the Western United States. Such technology promises to increase greatly our known mineral and fuel resources. A proposal is also being considered to equip a drilling ship, the Glomar Explorer, for sea-bottom exploration of the continental margin to well depths as great as $11,000 \mathrm{ft}$ below sea level.

In both the short and the long term, government understanding of natural-resource problems and consistent policies based on such understanding are essential. The future supply adequacy of many mineral commodities will be influenced less by physical scarcity of resources than by human or political factors. Potential investors are coming to realize that they must contribute to the technical development of the countries in which they are investing.

For future development, it is most important that governments commit themselves to long-term geologic mapping programs. Many areas of known mineral wealth are not yet adequately mapped; for instance, in Indonesia, only about 25 percent of a land area of more than 1.9 million square kilometers has been mapped geologically in some detail.

As the importance of developing countries as suppliers of minerals to the world increases, it is in everyone's interest that their resources be known. Geologic mapping, beginning with a countrywide small-scale map, is essential. A continuing geological survey operating as a permanent part of the government will help to lay the groundwork for mineral explorations. The personnel of a national geological survey can make a tremendously important contribution to the development of an effective national minerals policy.

\section{THE FUTURE}

\section{Predictions}

The overriding resource problem as we approach the 21 st century is energy - supply, demand, and cost. Despite differences of opinion about remaining petroleum reserves, it seems likely that, by the year 2000 , production of oil-and possibly of natural gas - will have passed its peak. Coal and other fossil fuels, together with nuclear fuels, will have to meet most of the increased demand for energy. Coal will be used in new ways to provide gaseous and liquid fuels. Hydrocarbons from oil shales and tar sands will become increasingly available, and alternative sources such as solar and geothermal energy will become increasingly important.

After the year 2000 , oil and gas are expected to decline further as energy sources, but they will remain important as sources for the petrochemical industry. Concurrently, oil shale and tar sands will be used on a large scale, but coal and nuclear fuels should be the major sources of energy. This assured supply of coal promises to buy the time needed to discover further supplies of nuclear fuel and to develop advanced nuclear technology. Alternative energy sources will increase in importance.

The increasing cost of energy will affect all phases of life and, regardless of what new sources are developed, will dictate more efficient and more conservative use of power. In the field of resources, energy cost will have a marked effect on mineral processing, at a time when increasing dependence on small mineral deposits and low-grade ores will require higher energy input. This problem could be alleviated by beneficiating minerals nearer the source by means of presently unused energy sources such as hydroelectric and geothermal power.

In projecting future demand for minerals, we are handicapped by rapidly changing technology; mere extrapolation of historical trends will not suffice. An example is the increased use of aluminum, magnesium, plastics, and fiberglass as substitutes for steel in automobiles. At present, according to the U.S. Bureau of Mines, world deficits are predicted by the year 2000 for asbestos, bismuth, fluorine, germanium, graphite, indium, mercury, sheet mica, silver, sulfur, and zinc. Because minerals are distributed unequally over the world, political and economic factors could well cause local shortages of other minerals as well. Further exploration and the efforts of countries to develop selfsufficiency in critical mineral commodities will not 
remove this threat. It will remain for mineral economists and planners with mining and minerals experience to play a role in developing government marketing policies based on recognition of world mineral interdependence.

Estimates of future resource availability are perforce based on present methods of exploration and analysis. These, too, will change, and new techniques already promise to reveal previously unknown resources at depth, both below the land and under the sea bottom. In the last few years, equipment that can explore with reflected sound waves to a depth of 30 to $70 \mathrm{~km}$ has been developed. This equipment has identified new areas for petroleum exploration in previously undetected sedimentary strata beneath crystalline rocks in both the Eastern and the Western United States. Such technology promises to increase greatly our known mineral and fuel resources. A proposal is also being considered to equip a drilling ship, the Glomar Explorer, for sea-bottom exploration of the continental margin to well depths as great as $11,000 \mathrm{ft}$ below sea level.

\section{The way ahead}

Participants in the International Centennial Symposium repeatedly expressed the conviction that national governments must give high priority to natural-resource policy. Their task will not be easy. Industrialized countries must establish conservation policies that will make the wisest possible use of nonrenewable resources. At the same time, they must continue to expand technical cooperation with developing countries on the basis of the modern nonexploitive view that a nation's resources are part of its natural heritage. Training is an important part of such a policy. It is also crucial that the results of resource studies be made widely available.

Governments of developing countries are faced with a dilemma in formulating a natural-resource policyhow to balance the immediate needs of the people against optimum long-term development of the country's resources. Demanding as they are, pressing immediate needs must not prevent the development of a long-term natural-resource policy based on a good knowledge of the nation's resources acquired by such fundamental studies as geologic mapping.

In discussions at the Symposium, it was agreed that the contribution of earth scientists to the development of national policy is needed now more than ever before and that it is likely to become more important in the future. To deal with the earth-science problems that will face us in the 21 st century, policymakers will need to depend more and more on the information furnished by earth scientists and on their analyses of the consequences of alternative actions.

The current shortage of technical personnel in developing countries reveals another aspect of the interdependence of nations. Specialized advice can be obtained from developed nations and from international organizations, and developing nations can pool their resources to attack common problems. Even though a nation may not have all the scientists that it needs, a cadre of trained resource personnel can serve a valuable function by interpreting resource-policy alternatives in their role as advisers to government.

The interdependence of nations for natural resources will, in the future, require greatly improved knowledge of mineral resources on a global scale. With the assistance of modern technology, a world data center could convert statistics into such readily usable tools as commodity maps plotted automatically from data files stored in digital form. Such an international resource would foster the development of world marketing policies that would reduce the risk of local shortages.

In summary, the International Centennial Symposium emphasized the interdependence of nations, the importance of socioeconomic factors in formulating natural-resource policy, and the incompleteness of our knowledge of what world resources are. It further agreed that people are the greatest resource of all. From the perspective of world resource needs, including optimum use of our environment, trained scientists, economists, and planners are a source of wisdom upon which the world must draw. 


\section{NATIONAL REPRESENTATIVES AND INVITED SPEAKERS, INTERNATIONAL}

\section{CENTENNIAL SYMPOSIUM}

[Invited speakers are marked with an asterisk(*)]

Argentina:

O. J. Ruiz-Huidobro

Australia:

C. S. Christian*

H. J. Vojacek*

Brazil:

Otto Bittencourt N.*

J. R. A. Ramos*

Lauro Sodre-Neto

\section{Canada:}
A. R. Berger
J. P. Bruce*
J. M. Harrison
D. J. McLaren*
W. F. Roberts*
J. M. Zarzycki*

Chile:

Carlos Ruiz*

China:

Ji-Qing Huang

Yan-Hau Lu

Shu-Ping Miao

Guang-Zhi Tu

Ji-Yang Wang

Da-He Xiong

Wen-You Zhang

Czechoslovakia:

Jaroslav Vesely

Vaclav Zika

Egypt:

M. F. El-Ramly

G. A. Moustafa*

Federal Republic of Germany:

F. N. Bender*

M. Kursten*

Bernhard Schmidt*

Fiji:

R. N. Richmond*

France:

Pierre-Noel Giraud

C. Guillemin*

Pierre Laffitte

Guy Pautot

Liliane Sardais

German Democratic Republic:

Gerd Olszek

Guatemala:

Samuel Bonis*

Guyana:

Irma Lowe
India:

T. N. Basu

V. S. Krishnaswamy

M. V. N. Murthy*

B. K. Rao

T.Thimmaiah

Indonesia:

Soetaryo Sigit*

Israel:

Uri Kafri

Japan:

Keichi Kasahara*

Y. Shimazaki*

Kenya:

E.M. Mwai

Korea (South):

Byung Koo Hyun*

Liberia:

W. A. Freeman

Nathaniel Richardson

C. S. Wotorson

Libya:

M. T. Busrewil

O. S. Hammuhda

Madagascar:

Roger Rambeloson

Mexico:

David Alvarez-Roblero

G. P. Salas*

M. A. Sosa Ordono

J. A. Villasana L.*

The Netherlands:

B. P. Hageman*

Nigeria:

J. A. Ogunkoya

Norway:

K. S. Heier

Kjell Glomnes

Pakistan:

S. A. Bilgrami*

Peru:

A. A. Giesecke*

The Philippines:

Angel Alejandrino*

Saudi Arabia:

Ahmed Al-Arinan

A. Y. Bagdady

Patrick Skipwith

Ghazi Sultan

A. Z. Yamani*
Sweden:

C. O. Ternryd*

Switzerland:

Ernst Spiess*

Thailand:

S. N. Kaewbaidhoon

Turkey:

Nezihi Canitez*

Union of Soviet Socialist Republics:

S. Kh. Negmatullaev

I. L. Nersesov*

A. V. Sidorenko

A. A. Trofimuk

R. Volkov

United Kingdom:

L. J. Harris*

I. G. Hughes

United States of America:

P. H. Abelson*

J. R. Balsley*

G. E. Becraft*

J. M. Botbol*

Philip Cohen*

J. S. Cragwall*

E. M. Davin*

A. L. Dilonardo*

F. J. Doyle*

R. E. Ehrenberg*

R. S. Fiske*

Philip Handler*

R. D. Kidwell*

D. M. Kinney*

C. D. Masters*

V. E. McKelvey*

J. O. Morgan*

D. R. Nichols*

W. C. Overstreet* (retired)

D. L. Peck*

D. F. Peterson*

J. R. Rapp*

R. W. Shaff*

R. B. Southard*

C. W. Sweetwood*

E. W. Vickers*

R. E. Wallace*

R. L. Wesson*

F. C. Whitmore, Jr.*

M. E. Williams*

A. N. Williamson*

N. P. Yingling*

Venezuela:

H. J. Lavie*

Yugoslavia:

Tomislav Ivanov

Mihajlo Siskovski

Zambia:

N. J. Money 
INTERGOVERNMENTAL AND INTERNATIONAL REPRESENTATIVES, INTERNATIONAL CENTENNIAL SYMPOSIUM

[Invited speakers are marked with an asterisk $(*)]$

Association of Geoscientists for International Development (Headquarters: Caracas, Venezuela):

D. E. Ajakaiye, President (Zaria, Nigeria)

R. A. Blais, Vice President (Montreal, Canada)

Emilio Herrero, Treasurer (Headquarters)

Alirio Bellizzia, General Secretary (Headquarters)

Victor Ricaldi, Executive Coordinator (Headquarters)

M. B. Katz, Editor (Australia)

S. D. Limaye, Editor (India)

Commission for the Geological Map of the World (Secretariat: Paris, France):

Frances Delany*, Secretary General

European Space Agency (Headquarters: Paris, France):

Gottfried Konecny*, Special Centennial Representative

Institute for International Mineral Resources Development (Headquarters: Shizuoka-ken, Japan): Chikao Nishiwaki*, President

Inter-American Development Bank (Headquarters: Washington, D.C.):

B. F. Grossling*, Natural Resources Advisor

International Atomic Energy Agency (Headquarters: Vienna, Austria):

James Cameron*, First Officer, Division of Nuclear Power and Reactors

International Bank for Reconstruction and Development of the World Bank (Headquarters: Washington, D.C.): Eric Saks, Senior Cartographer

Ulrich Boegli, Cartographer

Hans Stölle, Cartographer

International Geological Congress, 26th (Paris, France, July 1980):

Paul Sangnier, Secretary General

International Institute for Applied Systems Analysis (Headquarters: Schloss Laxenburg, Austria): Michel Grenon*, Director

International Union of Geological Sciences (Secretariat: Ottawa, Ontario, Canada):

Rudolph Trumpy*, President (Zurich, Switzerland)

W. W. Hutchison*, Secretary General (Ottawa, Ontario, Canada)

Vera Lafferty, Editor (Ottawa, Ontario, Canada)

International Water Resources Association (Headquarters: Buenos Aires, Argentina):

G. J. Cano*, President

Pan American Health Organization of the World Health Organization (Headquarters: Washington, D.C.): Santiago Pinzon, WHO Fellow from Mexico

United Nations (Headquarters: U.N. Building, New York, N.Y.):

Coordinating Committee Offshore Prospecting (U.N. Building, Bangkok, Thailand):

A. Johannas*, Project Manager, Regional Offshore Prospecting in East Asia

Department of Technical Cooperation for Development, Division of Natural Resources, Energy, and

Transport (U.N. Building, New York, N.Y.):

S. Alpan*, Interregional Adviser

Alexes Beus, Technical Adviser 

